Blenard Xhaferaj

http://dx.doi.org/10.21278/brod73101

\title{
INVESTIGATION ON SOME CONVENTIONAL HULLS FORMS OF THE PREDICTIVE ACCURACY OF A PARAMETRIC SOFTWARE FOR PRELIMINARY PREDICTIONS OF RESISTANCE AND POWER
}

UDC 629.5.015.2:629.5.01

Original scientific paper

\begin{abstract}
Summary
Preliminary prediction of resistance and power is a fundamental aspect of the ship design process since they directly influence the developments of the design process, fuel consumption and costs, and environmental impact from the early design stage. Parametric predictions of resistance and power, based mainly on statistical regression models that are also ideal for computer programming, are often performed during initial design stages, providing rapid predictions and optimisations for minimum resistance. The paper aims to present the results of the comparative analysis on some conventional hulls of the predictive accuracy of a computer program developed by the author for parametric predictions of resistance and power of ships. The program (entitled Ship Power V 1.0) is developed in the Visual Basic 6.0 environment based on two well-known regression models Holtrop and Van Oortmerssen. The program can perform detailed predictions of resistance and power, resistance coefficients, propeller thrust, hull efficiency, wake, and trust fractions, with no restriction on the number of velocities. In this study, only the analysis of the accuracy of resistance and power prediction is considered. Results of the comparative analysis of the computational procedures of Ship Power V 1.0 versus experimental data, and against results of another well-known commercial software, performed on three models of the Ridgely-Nevitt trawler series and KCS hull have shown a good level of accuracy and reliability as other well-known commercial software.
\end{abstract}

Key words: Resistance; power; regression models; ship design; experimental data

\section{Introduction}

Ship Power V 1.0 is a computer tool with Graphical User Interface (GUI) in Albanian and English for parametric predictions of resistance and power of ships, developed by the author in Visual Basic 6.0 environment. The software performs rapid predictions of resistance and power of ships within a certain level of accuracy and reliability. The paper aims to present the investigation of the predicting accuracy of this computer tool on some conventional hulls forms (fishing and containers hulls) to understand its level of accuracy if used in any preliminary 
procedure of the ship design process. Accuracy, reliability, and rapidity of predictions of resistance and power of ship for a specific speed imposed by owner requirements are among the most important aspects of the ship design process since a rapid and accurate evaluation of resistance and power not only allows a preliminary and reliable assessment of technical performances but also enables the assessment of economic and environmental impacts of a ship in operation since the initial design stage. For ship designers, it is also of particular importance to predict from the early design stage a preliminary value of resistance and power within a certain level of accuracy, analysing different solutions to find the best alternative that meets the owner and legislative requirements.

Obviously, the accuracy of results depends on the methodology used for the prediction of resistance and power. Experimental resistance tests, computational fluid dynamics (CFD) simulations, traditional standard systematic series, and methods based on statistical regression are possible options that ship designers have at their disposal for predicting the resistance. [1, 2] It is widely accepted that among different available options, the use of resistance experimental test data remains the most reliable option for predicting the resistance and power of ships. But, for conventional ships, statistical and regression calculations can provide predictions of resistance and power almost with the same reliability guaranteed by the experimental tests. [3] The choice of prediction method of resistance and power is affected by several factors such as the available capacity and tools, the level of accuracy, available funds, and the current development stage of the ship design process. [1,2]

Nowadays, Computational Fluid Dynamic (CFD) simulations are increasingly used for predictions of resistance of ships, becoming an important standard of ship design practices, as shown in references $[4,5,6,7,8,9]$. Despite this, it can be emphasized that these simulations are particularly appropriate when the main parameters of the ship, main dimensions, and hull form coefficients have been defined, or have a slight variance, and the main attention is focused on the variation of the local geometry of the hull form. But when the problem is the global optimization, where we face a high variance of the main parameters of the ship, these applications are not very practical because of the time required to perform the calculations. It is in this case that empirical and statistical methods are most appropriate. [10]

Technical literature of the field presents many papers that deal with the formulations of regressive statistical models, such as in references [11, 12, 13, 14, 15]. Many studies that use regression models for preliminary predictions and optimisations during the early design stage are carried out and presented in the literature. Some recent publications that have addressed and used statistical regression models in multi-criteria ship optimisations, parametric predictions of resistance and power, evolutionary algorithm and techniques for automation of hull form design, verifications with CFD and experimental data can be found in references $[10,16,17$, $18,19,20,21]$. A recent publication [22] provides helpful considerations on how to estimate Energy Efficiency Operational Indicator (EEOI), as part of Ship Energy Efficiency Management Plan (SEEMP) proposed by the International Maritime Organisation (IMO), based on the Automatic Identification System (AIS) data and application of Holtrop Mennen method. The study has also proposed approximate evaluations of those parameters required to perform calculations according to the Holtrop Mennen method, but not known from the AIS data.

Basically, the prediction accuracy of any computer tool depends on the theoretical computational models and algorithms used. The theoretical computational model of Ship Power V 1.0 is based on two well-known regression models, Holtrop Mennen and Van Oortmerssen. The program has a Graphical User Interface (GUI) in English and Albanian and can be used as a useful tool for the parametric prediction of resistance and power of ships. Although comparative analysis of the results of calculation of the software "Ship Power V 1.0" versus data of the examples provided in references $[12,13]$ was presented in [23], some other simple 
questions came out. For example, what is the predictive accuracy of this computer tool on some conventional hull forms? Is this computer tool reliable, as other well-known commercial software, for the preliminary power prediction from the early ship design stage? To answer the above questions was necessary to perform a comparative analysis of the results of calculations of "Ship Power V 1.0" versus experimental resistance data. The comparative analysis was limited only to those types of conventional hulls that have been used or appear to have the increasing potential for use in Albanian maritime activities. Fishing and container ship hulls were chosen for analysis and verifications. The paper presents the results of the comparative analysis performed on four hulls of ships. The comparative analysis was carried out on three models of the Ridgely Nevitt trawler systematic series and on the hull of Kriso Container Ship (KCS). For Ridgely Nevitt hulls, the comparative analysis was also carried out versus a wellknown commercial software. Forms of the Ridgely Nevitt series are forms used in some Albanian fishing vessels. The following sections of this paper present the results of the comparative analysis of models W-10, W-11, W-12 of the Ridgely Nevitt fishing vessels series and of the hull of the Kriso Container Ship (KCS).

\section{Materials and Methods}

The actual computational procedures of the software "Ship Power V 1.0" are computer procedures based on Holtrop-Mennen [12], Holtrop [13], and Van Oortmerssen [14, 24, 25] regressions. The general architecture, menus of software, Graphic User Interfaces (GUI), reports of calculations, and graphic representations of results of predictions of the software "Ship Power V 1.0, as well as differences and modifications between these procedures are presented in detail in references [23, 26]. Figure 1 [26] shows the general flow chart of the software.

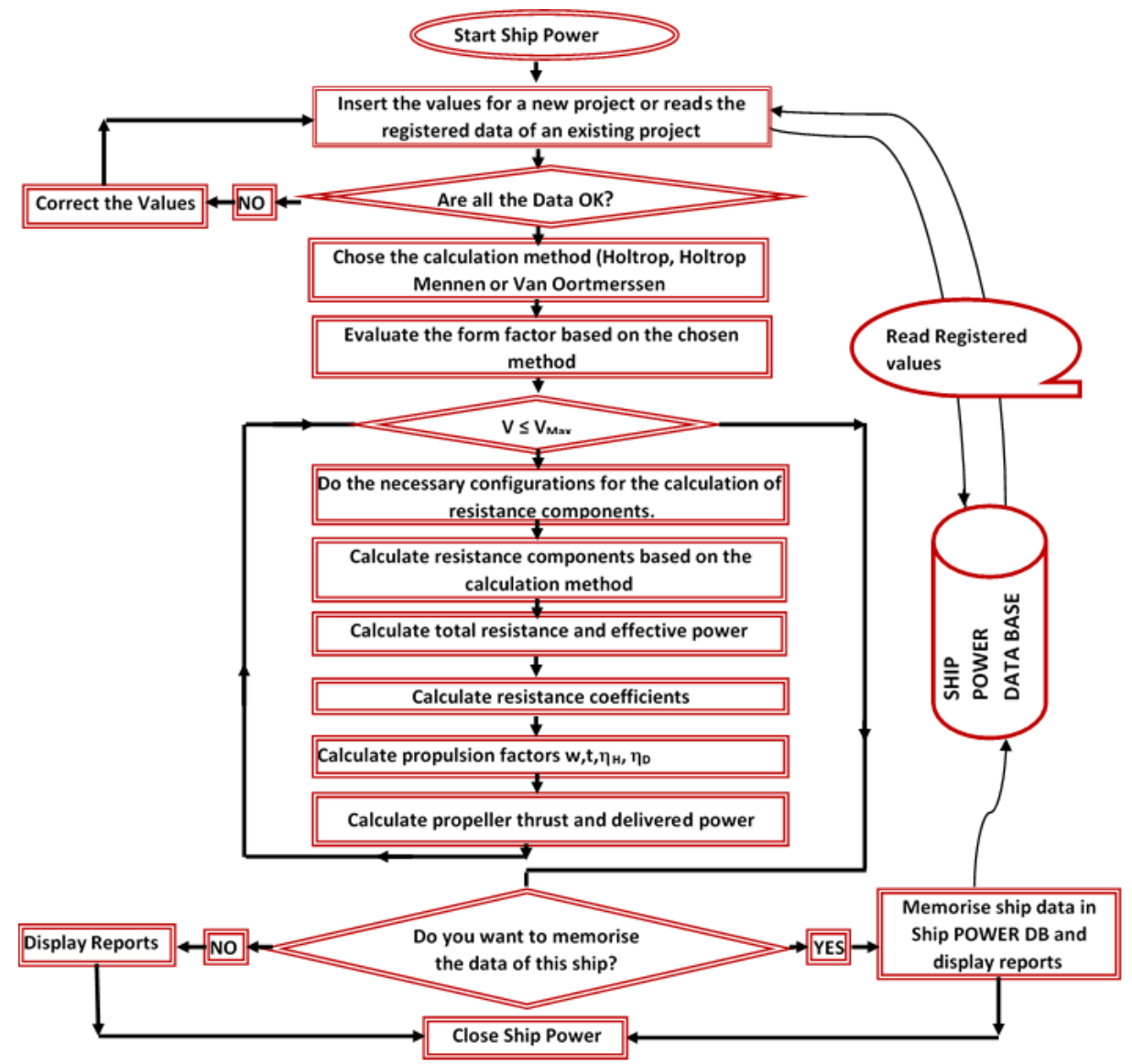

Fig. 1 The general flow chart of Ship Power V $1.0[23,26]$ 
Limits of the applicability of the regression models Holtrop, Holtrop-Mennen, and Van Oortmerssen, are presented in [11, 12, 13, 25]. Holtrop and Holtrop Mennen are similar procedures, but also they have some differences, which are based respectively on regression equations models as presented in references [13] and [12]. Compared to Holtrop Mennen in Holtrop computational procedure all suggestions and modifications as presented in reference [13] have been implemented. Reference [13] suggests that for values of Froude numbers higher than 0.40, the Holtrop regression model performs better than the Holtrop-Mennen regression model. The upper limit value of the Froude number is not explicitly expressed in reference [13]. But if we look carefully at the example taken into consideration, the maximum speed value corresponds to a Froude number of about 0.81. In "Ship Power V 1.0" the user can select the method of calculation through the Graphic User Interface (GUI) of the software and the respective dialoguing windows of the program. As reported in references [23, 26], by default, the calculation procedure is the procedure based on the regression analysis of Holtrop and Holtrop Mennen. For Froude numbers, up to 0.4, the program suggests the user to perform the calculations according to the Holtrop-Mennen regression. While for Froude numbers above 0.4, the program suggests the users to perform the calculations according to the Holtrop modifications, as described in reference [13].[23] The Van Oortmerssen procedure in the software "Ship Power V 1.0" is activated through the Graphical User Interface (GUI) when the user decides to perform the calculations according to the Van Oortmerssen regression. [26]

\subsection{Resistance and propulsion calculations structure of Ship Power V 1.0}

In cases of the models of regression Holtrop and Holtrop Mennen, the total hull resistance in "Ship Power V 1.0" is calculated as follows: [23]

$$
R_{T}=R_{F}\left(1+k_{1}\right)+R_{W}+R_{B}+R_{T R}+R_{A P P}+R_{A}+R_{A I R}+R_{M A R G I N}
$$

In the case of the Van Oortmerssen regression model, the total hull resistance in "Ship Power V 1.0" is calculated as follows: [26]

$$
R_{T}=R_{F}+R_{R}+R_{A P P}+R_{A}+R_{A I R}+R_{M A R G I N}
$$

Where $R_{F}$ is frictional resistance $\left(R_{F}\right)$ calculated according to the ITTC -1957 formula, $(1+k)$ is form factor, $R_{W}$ is wave resistance, $R_{R}$ is residual resistance, $R_{B}$ is additional resistance due to a bulbous bow, $R_{A P P}$ is appendages resistance, $R_{T R}$ is additional pressure resistance due to the immersed transom, $R_{A}$ is model ship correlation resistance. $R_{\text {Air }}$, is air resistance, calculated as in (Van Manen and Van Oossanen, 1988) [27], $R_{\text {Margin }}$ is additional resistance for meteorological conditions, calculated in the current version of the program as a percentage addition of the resistance in calm seas. In equation (1), components of resistance are calculated according to mathematical formulations presented in reference [12], in the case of the Holtrop Mennen regression, while in the case of the Holtrop regression, the computational procedure includes all the modifications presented in the reference [13], as reported in reference [23].

Resistance coefficients, power, propulsive thrust, hull efficiency, and quasi propulsive coefficient (QPC) are calculated as in (Xhaferaj and Dukaj, 2012, 2017) [23, 26].

\subsection{Procedure for validating the accuracy of results of the "Ship Power V 1.0" calculations}

To understand the accuracy of the computational procedures of the software "Ship Power V 1.0" against experimental data, or versus resistance data extrapolated from systematic hull series, or versus results of predictions from other commercial CAD-CAE platforms was developed a step-by-step procedure. Figure 2 presents the developed procedure.

The procedure corresponds to the following situations: 
- All parameters needed to run the software Ship Power V 1.0 are available, and a comparative analysis of results of calculation of "Ship Power V 1.0" versus experimental resistance data is to be carried out.

- Some of the parameters needed to run Ship Power V1.0 and a ship lines plan are available, and a comparative analysis of results of calculation of Ship Power V 1.0 versus experimental resistance data or resistance data extrapolated from systematic hull series is to be carried out.

- A ship lines plan or a table of offsets are available, and comparative analysis of results of calculations of "Ship Power V 1.0" versus results of calculations of other CAD-CAE platforms is to be carried out.

As presented in figure 2, there are some cases when the three-dimensional CAD hull geometry of the ship is needed. For such cases, was implemented a procedure for reconstructing the 3D CAD model of the hull starting from a table of offsets or a ship lines plan. In figure 3 is presented the 3D hull reconstruction procedure. Since the software "Ship Power V 1.0" cannot perform the geometric modelling of the hull, it is necessary to use a specialized CAD tool for the $3 \mathrm{D}$ hull reconstruction procedure.

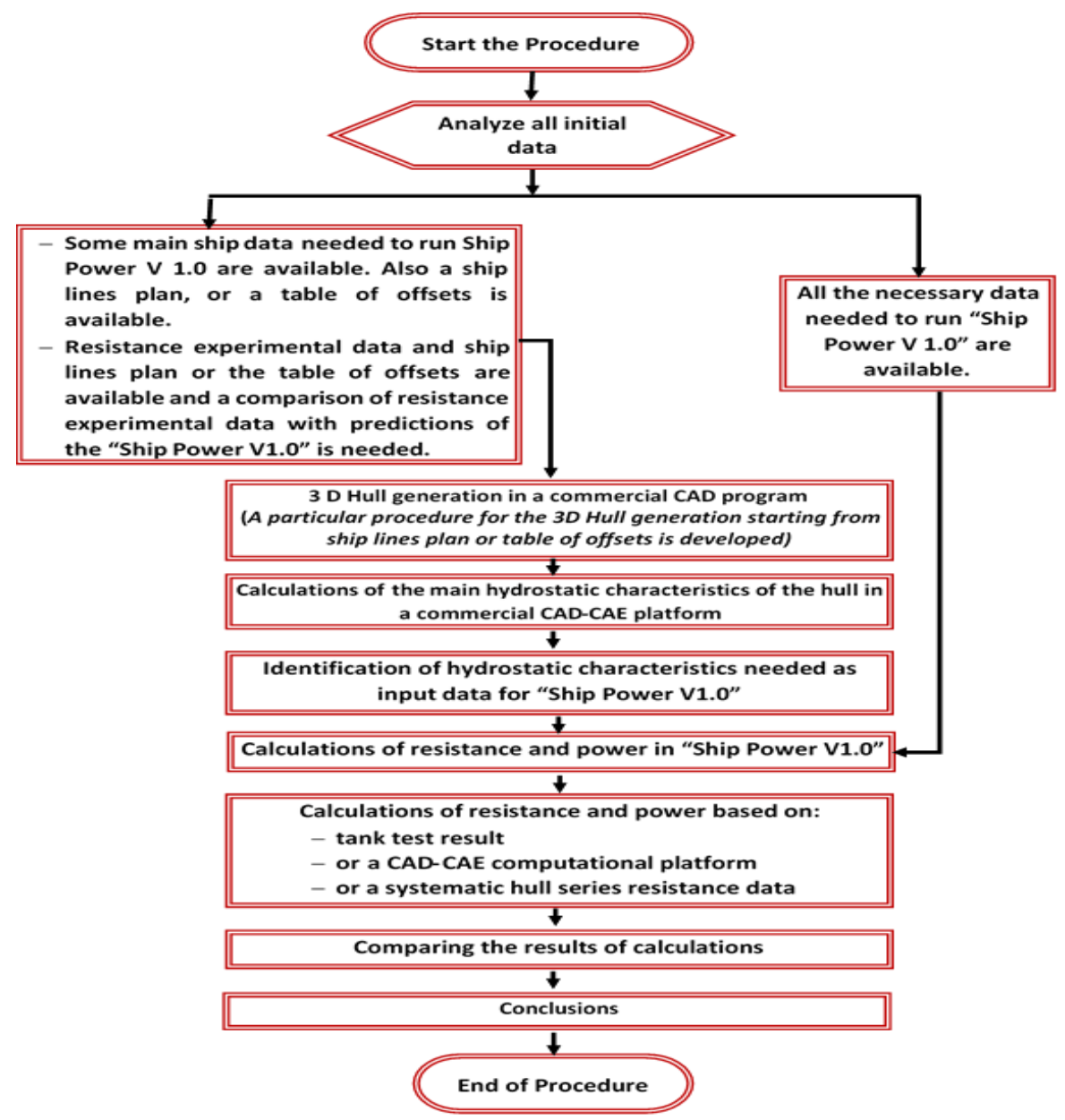

Fig. 2 The flowchart procedure for validating the accuracy of results of calculations of "Ship Power V 1.0"

2.3 3D ship hull modelling procedure starting from a table of offsets or a ship lines plan.

The analysis of resistance and power predictions in Ship Power V 1.0 requires some main ship parameters as input data. The minimum main parameters that Ship Power V 1.0 requires as input data are: length between perpendiculars $\mathrm{L}_{\mathrm{BP}}$, length on waterline $\mathrm{LwL}_{\mathrm{L}}$, bream $\mathrm{B}$, draft 
on forward perpendicular $T_{F P}$, draft on after perpendicular $T_{A P}$, block coefficient $C_{B}$, midship section coefficient $C_{M}$, water-plane area coefficient $C_{W L}$, and prismatic coefficient $C_{P}$, longitudinal centre of buoyancy $L C B$. It is important to note that, for the comparative analysis, the above parameters must not be seen only as numbers but as parameters that can significantly affect the overall accuracy of the results of calculations. If some of these parameters are unknown, they can be estimated approximately using ship design principles and formulas available in the literature, such as in references [1, 28, 29, 30, 31]. A more accurate approach to define these ship parameters if a ship lines plan is available is to generate the $3 \mathrm{D}$ model of the hull and to use this 3D CAD model in a CAD-CAE platform for the calculations of the hydrostatic characteristics necessary to run the software Ship Power V 1.0. This approach was used in this study. A specific procedure for 3D CAD modelling of an existing hull using data from a table of offsets or a ship line plan was implemented and presented in figure 3 .

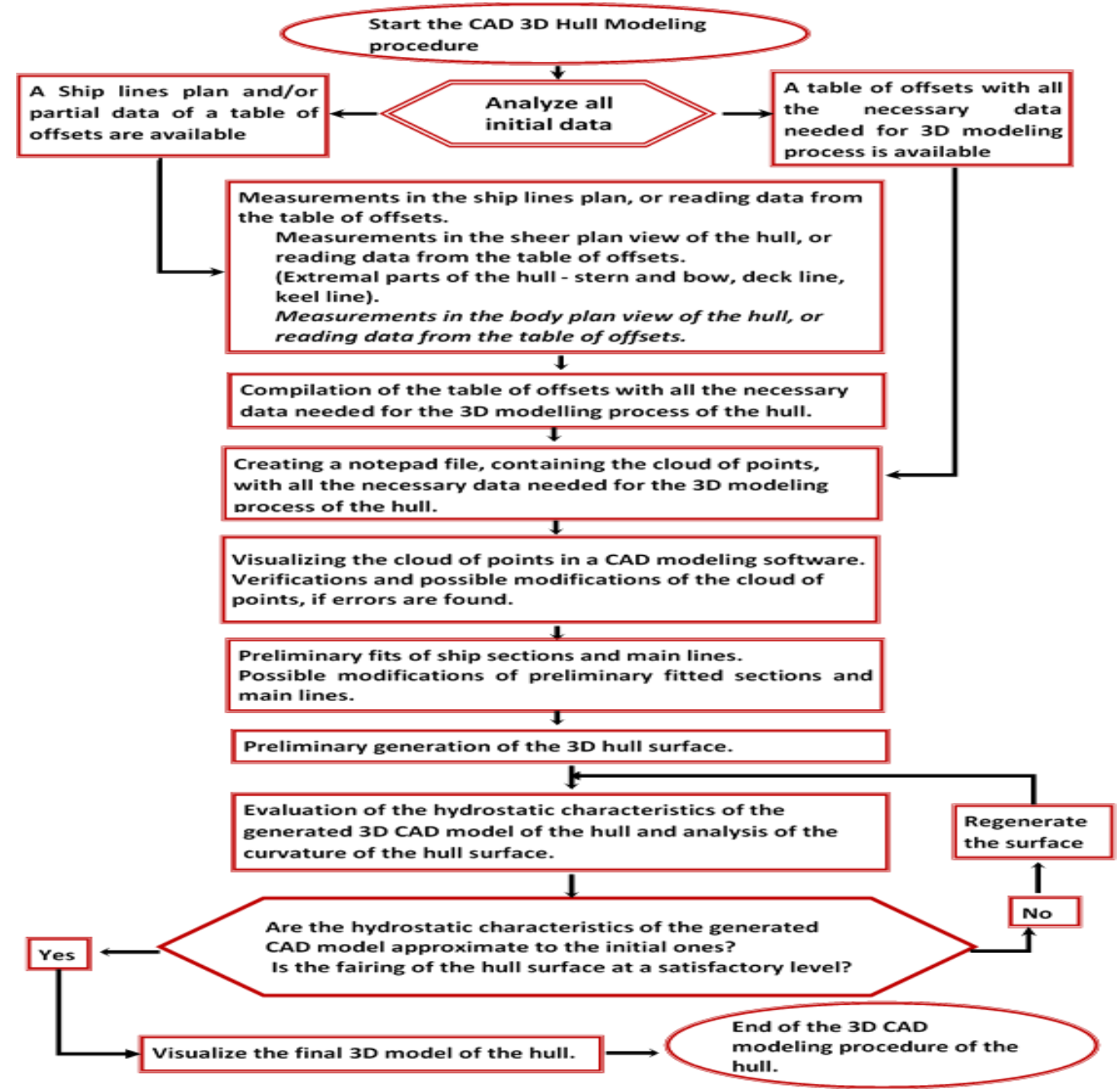

Fig. 3 The flowchart procedure for the 3D ship hull modelling procedure starting from a table of offsets or a ship lines plan. (Adapted from $[32,33,34,35]$ )

The modelling process consists of 4 main stages, as follows, and graphically presented in figure 4:

- Phase 1 - This phase includes all preparatory actions, such as analysis of available data, measurements in the ship lines plan, or reading data from the table of offsets. The final product of this phase is the generation of a notepad file containing the cloud of points of the 3D CAD model that is to be generated. Some applicative software, such as AUTOCAD, Excel, and Note Pad, can be used in this phase. 
- Phase 2 - This phase involves visualisations, verifications, possible modifications of the cloud of points, and the generation of main curves that fit better the cloud of points. The final product of this phase is the generation of a 3D wireframe model of the hull.

- Phase 3 - This phase involves the generation of the 3D hull surface that better fits its 3D wireframe model. The final product of this phase is the preliminary generation of the 3D surface model of the hull.

- Phase 4 - This phase is called the hull surface fairing phase and includes verifications, possible modifications, and analyses of curvature and hydrostatic characteristics. The final product of this phase is a 3D faired model of the hull, ready for further processing on CAE platforms.

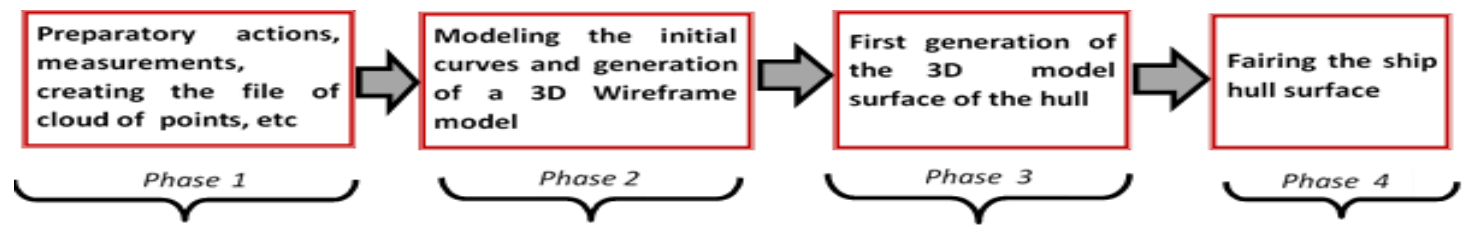

Fig. 4 Main phases of the 3D modelling process of the ship hull. (Adapted from [32, 33])

\section{Results}

The methodology and procedures, as described in the previous section, have been applied for the following cases:

- Three models of the Ridgely-Nevitt trawler series, W-10, W-11, W-12, were analysed.

- The Kriso Container Ship (KCS) hull form was also analysed.

For the hulls of the Ridgely Nevitt trawler series, in addition to the comparison versus experimental data, a comparison of the results of calculations of the software "Ship Power V 1.0" versus a well-known commercial software was also carried out.

A summary of the main characteristics of the hulls W-10, W-11, W-12, and of the Kriso Container Ship (KCS), as reported in [36, 37, 38, 39], is presented in table 1 . The experimental resistance data of the hulls $\mathrm{W}-10, \mathrm{~W}-11, \mathrm{~W}-12$, and $\mathrm{KCS}$, as reported in [37, 39], are presented in table 2.

Table 1 Summary of main particulars of hulls W-10, W-11, W-12, and KCS, as reported in [36, 37, 38, 39]

\begin{tabular}{|l|c|c|c|c|}
\hline \multirow{2}{*}{ Main Hull Particulars } & \multicolumn{3}{|c|}{ Ridgely - Nevitt } & \multirow{2}{*}{ KRISO (KCS) } \\
\cline { 2 - 4 } & $\mathrm{W}-10$ & $\mathrm{~W}-11$ & $\mathrm{~W}-12$ & \\
\hline Length Between perpendiculars, (in m) & 30.48 & 30.48 & 30.48 & 230.00 \\
\hline Beam, (in m) & 5.5 & 7.78 & 8.68 & 32.2 \\
\hline Draft, (in m) & 2.4 & 3.39 & 3.79 & 10.8 \\
\hline Block coefficient & 0.494 & 0.494 & 0.494 & 0.6505 \\
\hline Mid ship area coefficient & 0.76 & 0.76 & 0.76 & 0.985 \\
\hline Prismatic coefficient & 0.65 & 0.65 & 0.65 & 0.66 \\
\hline Water plane area coefficient & 0.779 & 0.779 & 0.779 & 0.820 \\
\hline Vertical prismatic coefficient & 0.634 & 0.634 & 0.634 & - \\
\hline LCB/LBP aft of F.P & 0.5155 & 0.5155 & 0.5155 & 0.51632 \\
\hline Wetted Surface, (in m2) & 205.78 & 291.25 & 324.32 & 9424 \\
\hline Semi angle of entrance, (in degrees) & 18 & 24.5 & 26 & 17.6 \\
\hline
\end{tabular}


Table 2 Experimental resistance data of hulls W-10, W-11, W-12, and KCS, as reported in [37, 39]

\begin{tabular}{|c|c|c|c|c|c|c|c|}
\hline \multicolumn{2}{|c|}{$\mathrm{W}-10$} & \multicolumn{2}{c|}{$\mathrm{W}-11$} & \multicolumn{2}{c|}{$\mathrm{W}-12$} & \multicolumn{2}{c|}{ KCS } \\
\hline $\begin{array}{c}\text { Speed } \\
(\mathrm{kn})\end{array}$ & $\begin{array}{c}\text { Resistance } \\
(\mathrm{N})\end{array}$ & $\begin{array}{c}\text { Speed } \\
(\mathrm{kn})\end{array}$ & $\begin{array}{c}\text { Resistance } \\
(\mathrm{N})\end{array}$ & $\begin{array}{c}\text { Speed } \\
(\mathrm{kn})\end{array}$ & $\begin{array}{c}\text { Resistance } \\
(\mathrm{N})\end{array}$ & $\begin{array}{c}\text { Speed } \\
(\mathrm{kn})\end{array}$ & $\begin{array}{c}\text { Resistance } \\
(\mathrm{N})\end{array}$ \\
\hline 5.37 & 2837.97 & 6.04 & 5871.65 & 6.72 & 8447.17 & 16 & 836934 \\
\hline 6.04 & 3678.68 & 6.72 & 7388.5 & 7.39 & 10898.14 & 17 & 874030 \\
\hline 6.72 & 4661.74 & 7.39 & 9261.2 & 8.06 & 13171.18 & 18 & 938772 \\
\hline 7.39 & 5769.34 & 8.06 & 11209.52 & 8.73 & 16453.97 & 19 & 1044316 \\
\hline 8.06 & 7094.91 & 8.73 & 13811.73 & 9.4 & 22410.14 & 20 & 1167994 \\
\hline 8.73 & 8629.55 & 9.4 & 18722.56 & 10.07 & 30096.67 & 21 & 1292218 \\
\hline 9.4 & 11369.7 & 10.07 & 26987.36 & 10.74 & 38846.32 & 22 & 1451701 \\
\hline 9.74 & 14056.4 & 10.74 & 35705.87 & 11.42 & 47907.35 & 23 & 1617191 \\
\hline 10.07 & 16458.42 & 11.41 & 43285.64 & 12.09 & 60985.12 & 24 & 1857949 \\
\hline 10.4 & 18638.04 & 12.09 & 52720.32 & 12.76 & 83092.78 & 25 & 2289283 \\
\hline 10.74 & 20461.82 & 12.76 & 69080.88 & 13.43 & 118634.07 & 26 & 2827303 \\
\hline 11.03 & 22129.902 & 13.43 & 95160.81 & 14.1 & 173792.02 & $=$ & $=$ \\
\hline 11.41 & 23886.95 & 14.1 & 136311.3 & 14.77 & 246387.00 & $=$ & $=$ \\
\hline 11.75 & 25755.2 & 14.77 & 192492.34 & $=$ & $=$ & $=$ & $=$ \\
\hline 12.09 & 28201.73 & $=$ & $=$ & $=$ & $=$ & $=$ & $=$ \\
\hline 12.76 & 35630.26 & $=$ & $=$ & $=$ & $=$ & $=$ & $=$ \\
\hline 13.43 & 47195.63 & $=$ & $=$ & $=$ & $=$ & $=$ & $=$ \\
\hline 14.1 & 63387.16 & $=$ & $=$ & $=$ & $=$ & $=$ & $=$ \\
\hline 14.77 & 85138.96 & $=$ & $=$ & $=$ & $=$ & $=$ & $=$ \\
\hline 15.1 & 98572.6 & $=$ & $=$ & $=$ & $=$ & $=$ & $=$ \\
\hline
\end{tabular}

3.1 Results for the models W-10, W-11, and W-12 of the Ridgely-Nevitt series.

Models W-10, W-11, and W-12 are three hull models of the well-known Ridgely Nevitt trawler hull forms series. Models have respective values of displacement-length ratio equal to 200, 400, 500, and a prismatic coefficient $\mathrm{Cp}=0.65$. [36, 37] In table 2 are presented the experimental resistance data of these hulls as reported in (Claytor et al., 1956) [37]. For these hulls of the Ridgely Nevitt trawler series comparison of the results of calculations of the software "Ship Power V 1.0" versus Maxsurf-Resistance commercial software was also carried out. Also, for these hulls, reconstructions of 3D CAD models were performed. The 3D CAD models were re-constructed applying the flow chart presented in figure 3, geometrical data (drawings and table of offsets) as reported in (Nevitt, 1963; Claytor et al., 1956) [36, 37], and the transforming capacity of the CAD software used for the modelling process. The cloud of points of each model consisted of around 230 points containing information from lines of sections, the profile line of the bow, and the profile line of the stern. The commercial software used to generate the 3D models of these hulls was the software Maxsurf-Modeler. To assure that the generated 3D hulls models fitted the data of the real models $\mathrm{W}-10 ; \mathrm{W}-11 ; \mathrm{W}-12$, the 3D CAD models were checked against the main known parameters as presented in table 1 , and the process of generation of the surfaces of the 3D hull was repeated until a very satisfactory level of approximations were achieved. Figures 5, 6,7 show the wireframe and surface model of the 3D modelled hulls.

The software used to analyse the 3D CAD models was Maxsurf Resistance. Prediction of resistance and power according to the computational procedures of Van Oortmerssen and 
Holtrop were performed for the same velocities as the experimental data. Tables 3,4 show the results of calculations of resistance and the respective comparisons with experimental data for models W-10, W-11, and W-12 as obtained using the software Maxsurf-Resistance, according to Holtrop and Van Oortmerssen computational procedures.

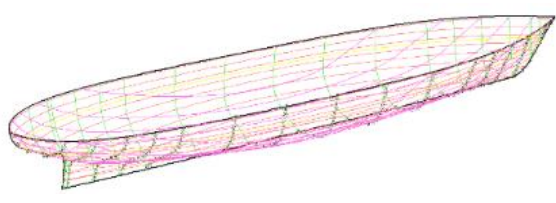

a) 3D Wireframe model.

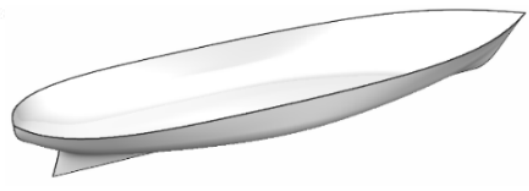

b) 3D surface model

Fig. 5 3D model of the model W-10 of Ridgely Nevitt Trawler hull form series

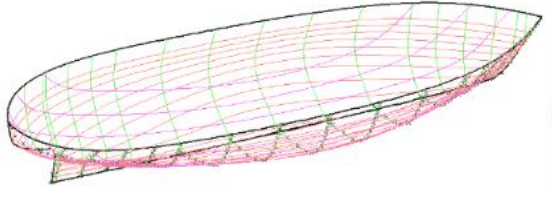

a) 3D Wireframe model.

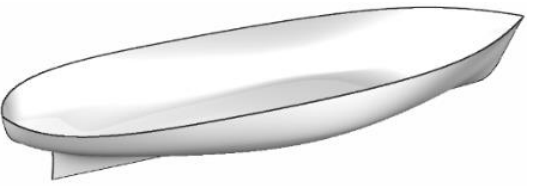

b) 3D surface model

Fig. 6 3D model of the model W-11 of the Ridgely Nevitt Trawler hull form series

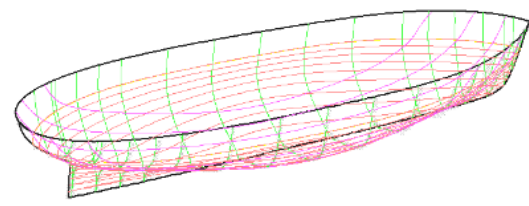

a) 3D Wireframe model.

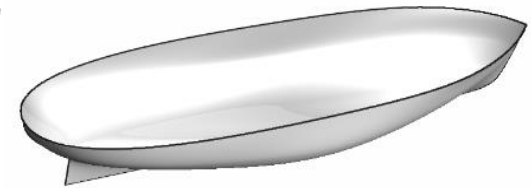

b) 3D surface model

Fig. 7 3D model of the model W-12 of Ridgely Nevitt Trawler hull form series

Table 3 Results of the comparative analyses of Holtrop computational procedure of Maxsurf Resistance vs. experimental data for models W-10, W-11, W-12, of the Ridgely Nevitt series

\begin{tabular}{|c|c|c|c|c|c|c|c|c|c|c|}
\hline \multirow{2}{*}{$V_{S}(\mathrm{kn})$} & \multirow{2}{*}{$\mathrm{FN}$} & \multicolumn{2}{|c|}{$\mathrm{W}-10-$ Holtrop Maxsurf } & \multicolumn{2}{|c|}{$\mathrm{W}-11-$ Holtrop Maxsurf } & \multicolumn{2}{|c|}{$\mathrm{W}-12-$ Holtrop Maxsurf } \\
\hline & & $\mathrm{R}_{\mathrm{T}}(\mathrm{N})$ & EXP $(\mathrm{N})$ & Dif \% & $\mathrm{R}_{\mathrm{T}}(\mathrm{N})$ & $\mathrm{EXP}(\mathrm{N})$ & Dif \% & $\mathrm{R}_{\mathrm{T}}(\mathrm{N})$ & EXP (N) & Dif \% \\
\hline 6.04 & 0.18 & 3566 & 3679 & -3.1 & 5289 & 5872 & -9.9 & $=$ & $=$ & $=$ \\
\hline 6.72 & 0.20 & 4551 & 4662 & -2.4 & 6695 & 7388 & -9.4 & 7520 & 8447 & -11.0 \\
\hline 7.39 & 0.22 & 5813 & 5769 & 0.8 & 8539 & 9261 & -7.8 & 9506 & 10898 & -12.8 \\
\hline 8.06 & 0.24 & 7464 & 7095 & 5.2 & 11142 & 11210 & -0.6 & 12310 & 13171 & -6.5 \\
\hline 8.73 & 0.25 & 9596 & 8630 & 11.2 & 14693 & 13812 & 6.4 & 16190 & 16454 & -1.6 \\
\hline 9.40 & 0.27 & 12729 & 11370 & 12.0 & 20253 & 18723 & 8.2 & 22276 & 22410 & -0.6 \\
\hline 10.07 & 0.29 & 16760 & 16458 & 1.8 & 29098 & 26987 & 7.8 & 32417 & 30097 & 7.7 \\
\hline 10.74 & 0.31 & 20513 & 20462 & 0.2 & 39083 & 35706 & 9.5 & 44692 & 38846 & 15.0 \\
\hline 11.41 & 0.33 & 23991 & 23887 & 0.4 & 47975 & 43286 & 10.8 & 55956 & 47907 & 16.8 \\
\hline 12.09 & 0.35 & 28640 & 28202 & 1.6 & 58384 & 52720 & 10.7 & 68748 & 60985 & 12.7 \\
\hline 12.76 & 0.37 & 35847 & 35630 & 0.6 & 74658 & 69081 & 8.1 & 88461 & 83093 & 6.5 \\
\hline 13.43 & 0.39 & 47042 & 47196 & -0.3 & 101942 & 95161 & 7.1 & 121904 & 118634 & 2.8 \\
\hline 14.10 & 0.41 & 59839 & 63387 & -5.6 & 130097 & 136311 & -4.6 & 155795 & 173792 & -10.4 \\
\hline 14.77 & 0.43 & 71881 & 85139 & -15.6 & 153825 & 192492 & -20.1 & 183653 & 246387 & -25.5 \\
\hline 15.10 & 0.44 & 77837 & 98573 & -21.0 & $=$ & $=$ & $=$ & $=$ & $=$ & $=$ \\
\hline
\end{tabular}



parametric software for preliminary predictions of resistance and power.

Table 4 Results of the comparative analyses of Van Oortmerssen computational procedure of Maxsurf Resistance vs. experimental data for models W-10, W-11, W-12, of the Ridgely Nevitt

\begin{tabular}{|c|c|c|c|c|c|c|c|c|c|c|}
\hline \multirow{2}{*}{$\begin{array}{c}V_{S} \\
(\mathrm{kn})\end{array}$} & \multirow{2}{*}{ FN } & \multicolumn{3}{|c|}{$\begin{array}{c}\text { W-10 - Van Oortmerssen } \\
\text { Maxsurf }\end{array}$} & \multicolumn{3}{|c|}{$\begin{array}{c}\text { W-11 - Van Oortmerssen } \\
\text { Maxsurf }\end{array}$} & \multicolumn{3}{|c|}{$\begin{array}{c}\text { W-12 - Van Oortmerssen } \\
\text { Maxsurf }\end{array}$} \\
\hline & & $R_{T}(\mathrm{~N})$ & $\begin{array}{c}\text { EXP } \\
(\mathrm{N})\end{array}$ & Dif \% & $R_{T}(\mathrm{~N})$ & $\begin{array}{l}\text { EXP } \\
(\mathrm{N})\end{array}$ & $\begin{array}{c}\text { Dif } \\
\%\end{array}$ & $R_{T}(\mathrm{~N})$ & $\begin{array}{l}\mathrm{EXP} \\
(\mathrm{N})\end{array}$ & $\begin{array}{c}\text { Dif } \\
\%\end{array}$ \\
\hline 6.04 & 0.18 & 3426 & 3679 & -6.9 & & 5872 & -2.6 & $=$ & $=$ & $=$ \\
\hline 6.72 & 0.20 & 4256 & 4662 & -8.7 & 7149 & 7388 & -3.2 & 8398 & 8447 & -0.6 \\
\hline 7.39 & 0.22 & 5215 & 5769 & -9.6 & 8781 & 9261 & -5.2 & 10285 & 10898 & -5.6 \\
\hline 8.06 & 0.24 & 6467 & 7095 & -8.8 & 10974 & 11210 & -2.1 & 12961 & 13171 & -1.6 \\
\hline 8.73 & 0.25 & 8268 & 8630 & -4.2 & 14018 & 13812 & 1.5 & 16158 & 16454 & -1.8 \\
\hline 9.40 & 0.27 & 9772 & 11370 & -14.1 & 16525 & 18723 & -11.7 & 19730 & 22410 & -12.0 \\
\hline 10.07 & 0.29 & 14725 & 16458 & -10.5 & 25996 & 26987 & -3.7 & 31196 & 30097 & 3.7 \\
\hline 10.74 & 0.31 & 21469 & 20462 & 4.9 & 38209 & 35706 & 7.0 & 43588 & 38846 & 12.2 \\
\hline 11.41 & 0.33 & 25501 & 23887 & 6.8 & 44371 & 43286 & 2.5 & 49051 & 47907 & 2.4 \\
\hline 12.09 & 0.35 & 27449 & 28202 & -2.7 & 46698 & 52720 & -11.4 & 52998 & 60985 & -13.1 \\
\hline 12.76 & 0.37 & 31423 & 35630 & -11.8 & 53909 & 69081 & -22.0 & 65288 & 83093 & -21.4 \\
\hline 13.43 & 0.39 & 40470 & 47196 & -14.3 & 71741 & 95161 & -24.6 & 90336 & 118634 & -23.9 \\
\hline 14.10 & 0.41 & 54824 & 63387 & -13.5 & 100049 & 136311 & -26.6 & 125847 & 173792 & -27.6 \\
\hline 14.77 & 0.43 & 72772 & 85139 & -14.5 & 134923 & 192492 & -29.9 & 166283 & 246387 & -32.5 \\
\hline 15.10 & 0.44 & 82228 & 98573 & -16.6 & $=$ & $=$ & $=$ & $=$ & $=$ & $=$ \\
\hline
\end{tabular}

Models W-10, W-11, and W-12 were also analysed using the software "Ship Power V 1.0". In figures 8, 9 are presented the Graphic User Interface (GUI) of the software "Ship Power $\mathrm{V} 1.0$ " with the parametric data of models $\mathrm{W}-10$ and $\mathrm{W}-12$. Calculations of resistance and power according to the computational procedures Holtrop and Van Oortmerssen were performed for the same velocities as the experimental data.

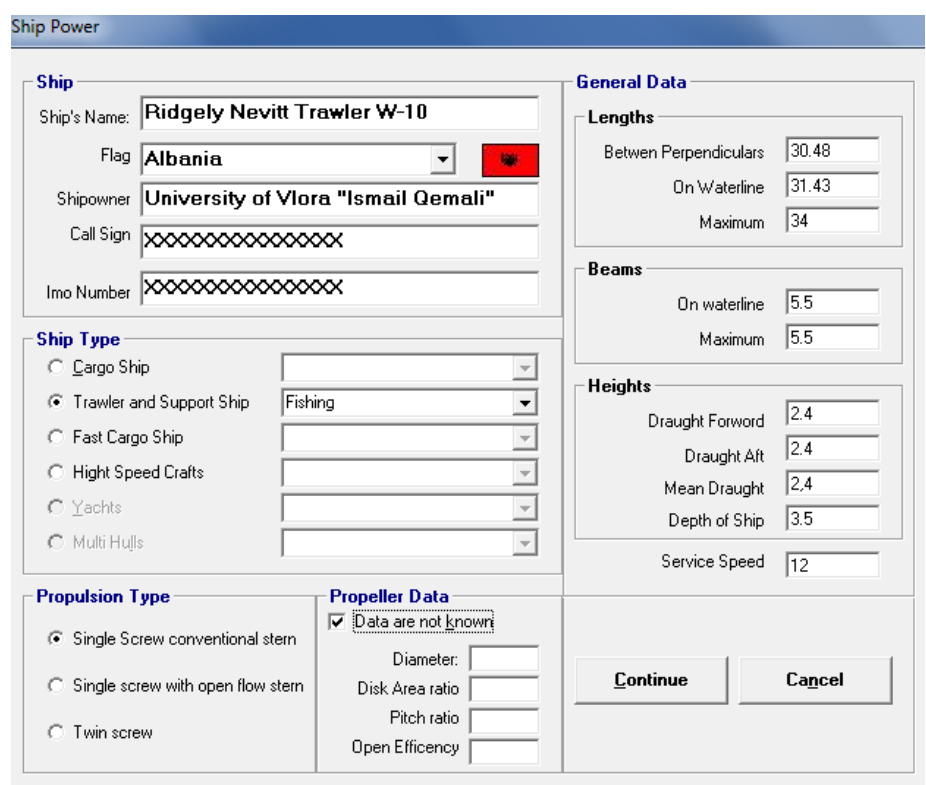

Fig. 8 One of the Graphical User Interfaces (GUI) of the software "Ship Power V 1.0", with the parametric data of the model W-10 of the Ridgely Nevitt trawler series 


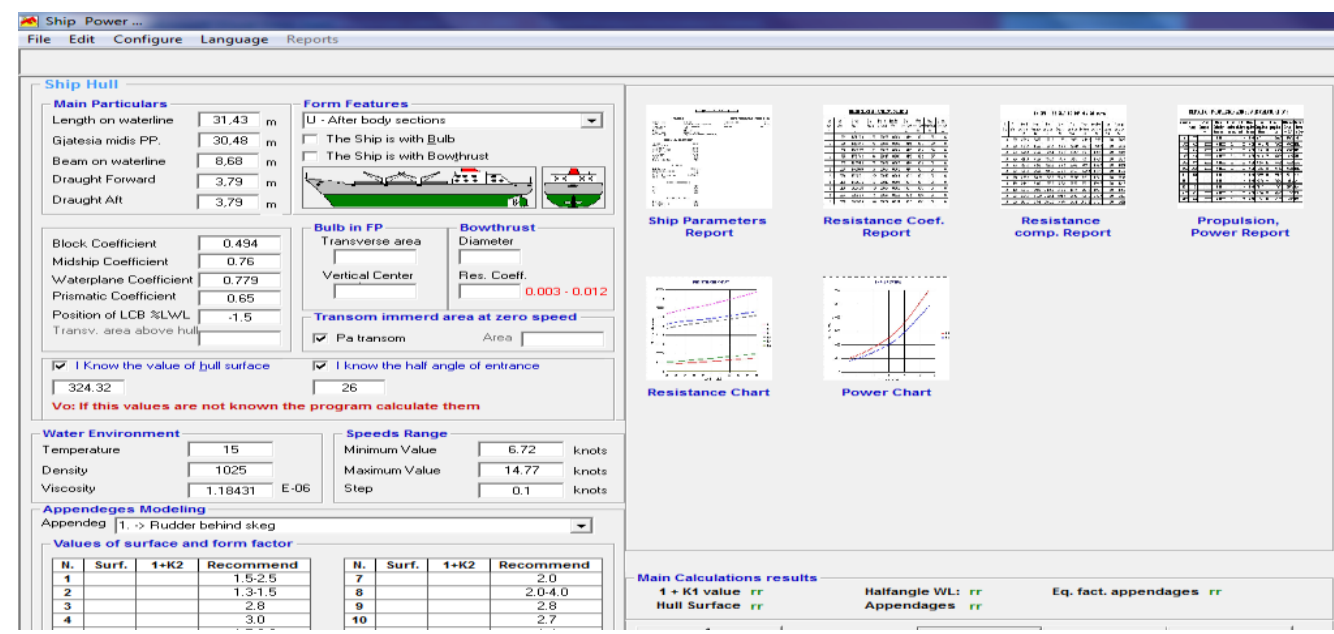

Fig. 9 One of the Graphical User Interfaces (GUI) of the software "Ship Power V 1.0", with the parametric data of the model W-12 of the Ridgely Nevitt trawler series

Tables 5, 6 show the calculations of resistance as obtained using the software "Ship Power V 1.0", according to Van Oortmerssen and Holtrop computational procedures, and the respective comparisons with experimental data for models $\mathrm{W}-10, \mathrm{~W}-11$, and W-12. Graphical comparisons of the results of calculations, as obtained from both computer programs (MaxsurfResistance and Ship Power V 1.0) versus experimental data, for the computational procedures Holtrop and Van Oortmerssen, for models W-10, W-11, and W-12 are presented in figures 10, 11. A break-down into resistance components of the W-10 model of the Ridgely-Nevitt trawler series as calculated by the software "Ship Power V 1.0" is presented in figure 12.

Table 5 Results of the comparative analyses of Holtrop computational procedure of "Ship Power V 1.0" vs. experimental data for models W-10, W-11, W-12, of the Ridgely Nevitt

\begin{tabular}{|c|c|c|c|c|c|c|c|c|c|c|}
\hline \multirow{2}{*}{$\begin{array}{c}V s \\
(\mathrm{kn})\end{array}$} & \multirow{2}{*}{$F N$} & \multicolumn{3}{|c|}{$\begin{array}{c}\text { W-10 - Holtrop } \\
\text { Ship Power V } 1.0\end{array}$} & \multicolumn{3}{|c|}{$\begin{array}{l}\text { W-11 - Holtrop } \\
\text { Ship Power V } 1.0\end{array}$} & \multicolumn{3}{|c|}{$\begin{array}{l}\text { W-12 - Holtrop } \\
\text { Ship Power V } 1.0\end{array}$} \\
\hline & & $\begin{array}{l}R_{T} \\
(\mathrm{~N})\end{array}$ & $\begin{array}{l}\text { EXP } \\
(N)\end{array}$ & $\begin{array}{c}\text { Dif } \\
\%\end{array}$ & $\begin{array}{l}R_{T} \\
(\mathrm{~N})\end{array}$ & $\begin{array}{c}\text { EXP } \\
(\mathrm{N})\end{array}$ & $\begin{array}{c}\text { Dif } \\
\%\end{array}$ & $\begin{array}{l}R_{T} \\
(\mathrm{~N})\end{array}$ & $\begin{array}{c}\text { EXP } \\
(\mathrm{N})\end{array}$ & $\begin{array}{c}\text { Dif } \\
\%\end{array}$ \\
\hline 6.04 & 0.18 & 3552 & 3679 & -3.4 & 5383 & 5872 & -8.3 & $=$ & $=$ & $=$ \\
\hline 6.72 & 0.20 & 4528 & 4662 & -2.9 & 6824 & 7388 & -7.6 & 7753 & 8447 & -8.2 \\
\hline 7.39 & 0.22 & 5849 & 5769 & 1.4 & 8664 & 9261 & -6.5 & 9736 & 10898 & -10.7 \\
\hline 8.06 & 0.24 & 7391 & 7095 & 4.2 & 11429 & 11210 & 2.0 & 12779 & 13171 & -3.0 \\
\hline 8.73 & 0.25 & 9361 & 8630 & 8.5 & 14386 & 13812 & 4.2 & 16042 & 16454 & -2.5 \\
\hline 9.40 & 0.27 & 13202 & 11370 & 16.1 & 20684 & 18723 & 10.5 & 22713 & 22410 & 1.3 \\
\hline 10.07 & 0.29 & 17580 & 16458 & 6.8 & 31393 & 26987 & 16.3 & 35077 & 30097 & 16.5 \\
\hline 10.74 & 0.31 & 20388 & 20462 & -0.4 & 40472 & 35706 & 13.3 & 46818 & 38846 & 20.5 \\
\hline 11.41 & 0.33 & 22988 & 23887 & -3.8 & 46804 & 43286 & 8.1 & 55085 & 47907 & 15.0 \\
\hline 12.09 & 0.35 & 27394 & 28202 & -2.9 & 55756 & 52720 & 5.8 & 65883 & 60985 & 8.0 \\
\hline 12.76 & 0.37 & 34860 & 35630 & -2.2 & 71987 & 69081 & 4.2 & 85291 & 83093 & 2.6 \\
\hline 13.43 & 0.39 & 46655 & 47196 & -1.1 & 100297 & 95161 & 5.4 & 119756 & 118634 & 0.9 \\
\hline 14.10 & 0.41 & 63634 & 63387 & 0.4 & 145586 & 136311 & 6.8 & 176318 & 173792 & 1.5 \\
\hline 14.77 & 0.43 & 85728 & 85139 & 0.7 & 211379 & 192492 & 9.8 & 260937 & 246387 & 5.9 \\
\hline 15.10 & 0.44 & 98157 & 98573 & -0.4 & $=$ & $=$ & $=$ & $=$ & $=$ & $=$ \\
\hline
\end{tabular}



parametric software for preliminary predictions of resistance and power.

Table 6 Results of the comparative analyses of Van Oortmerssen computational procedure of "Ship Power V 1.0" vs. experimental data for models W-10, W-11, W-12, of the Ridgely Nevitt

\begin{tabular}{|c|c|c|c|c|c|c|c|c|c|c|}
\hline \multirow{2}{*}{$\begin{array}{c}V_{S} \\
(\mathrm{kn})\end{array}$} & \multirow{3}{*}{$F N$} & \multicolumn{3}{|c|}{$\begin{array}{c}\text { W-10-Van } \\
\text { Oortmerssen }\end{array}$} & \multicolumn{3}{c|}{$\begin{array}{c}\text { W-11-Van } \\
\text { Oortmerssen } \\
\text { Ship Power V 1.0 }\end{array}$} & \multicolumn{3}{c|}{$\begin{array}{c}\text { W-12-Van } \\
\text { Oortmerssen } \\
\text { Ship Power V 1.0 }\end{array}$} \\
\cline { 3 - 13 } & & $R_{T}(\mathrm{~N})$ & $\begin{array}{c}\text { EXP } \\
(\mathrm{N})\end{array}$ & $\begin{array}{c}\text { Dif } \\
\%\end{array}$ & $R_{T}(\mathrm{~N})$ & $\begin{array}{c}\text { EXP } \\
(\mathrm{N})\end{array}$ & $\begin{array}{c}\text { Dif } \\
\%\end{array}$ & $\begin{array}{c}R_{T} \\
(\mathrm{~N})\end{array}$ & $\begin{array}{c}\text { EXP } \\
(\mathrm{N})\end{array}$ & $\begin{array}{c}\text { Dif } \\
\%\end{array}$ \\
\hline 6.04 & 0.18 & 3735 & 3679 & 1.5 & 6157 & 5872 & 4.9 & $=$ & $=$ & $=$ \\
\hline 6.72 & 0.20 & 4638 & 4662 & -0.5 & 7691 & 7388 & 4.1 & 9017 & 8447 & 6.7 \\
\hline 7.39 & 0.22 & 5673 & 5769 & -1.7 & 9416 & 9261 & 1.7 & 11002 & 10898 & 1.0 \\
\hline 8.06 & 0.24 & 7106 & 7095 & 0.2 & 11924 & 11210 & 6.4 & 14027 & 13171 & 6.5 \\
\hline 8.73 & 0.25 & 8946 & 8630 & 3.7 & 14900 & 13812 & 7.9 & 17093 & 16454 & 3.9 \\
\hline 9.40 & 0.27 & 10723 & 11370 & -5.7 & 18096 & 18723 & -3.3 & 21532 & 22410 & -3.9 \\
\hline 10.07 & 0.29 & 16277 & 16458 & -1.1 & 28545 & 26987 & 5.8 & 33951 & 30097 & 12.8 \\
\hline 10.74 & 0.31 & 23154 & 20462 & 13.2 & 40338 & 35706 & 13.0 & 45534 & 38846 & 17.2 \\
\hline 11.41 & 0.33 & 26984 & 23887 & 13.0 & 45839 & 43286 & 5.9 & 50128 & 47907 & 4.6 \\
\hline 12.09 & 0.35 & 29041 & 28202 & 3.0 & 48933 & 52720 & -7.2 & 54959 & 60985 & -9.9 \\
\hline 12.76 & 0.37 & 33673 & 35630 & -5.5 & 58310 & 69081 & -15.6 & 69810 & 83093 & -16.0 \\
\hline 13.43 & 0.39 & 43723 & 47196 & -7.4 & 78647 & 95161 & -17.4 & 97707 & 118634 & -17.6 \\
\hline 14.10 & 0.41 & 59119 & 63387 & -6.7 & 108822 & 136311 & -20.2 & 135194 & 173792 & -22.2 \\
\hline 14.77 & 0.43 & 77934 & 85139 & -8.5 & 144506 & 192492 & -24.9 & 176263 & 246387 & -28.5 \\
\hline 15.10 & 0.44 & 87726 & 98573 & -11.0 & $=$ & $=$ & $=$ & $=$ & $=$ & $=$ \\
\hline
\end{tabular}

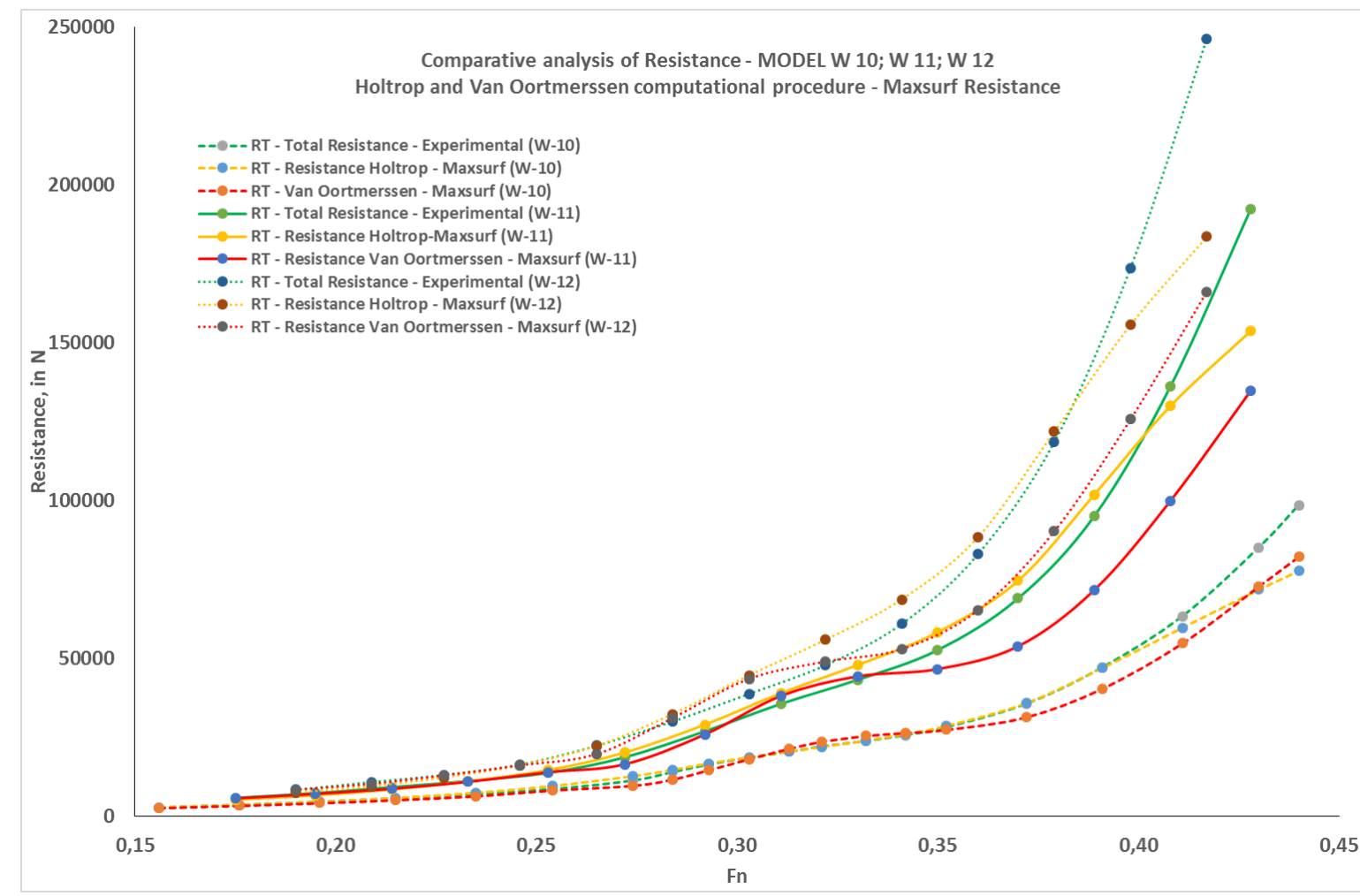

Fig. 10 Graphical comparison of the results of calculations obtained from Maxsurf Resistance vs. experimental data for Holtrop and Van Oortmerssen computational procedures 


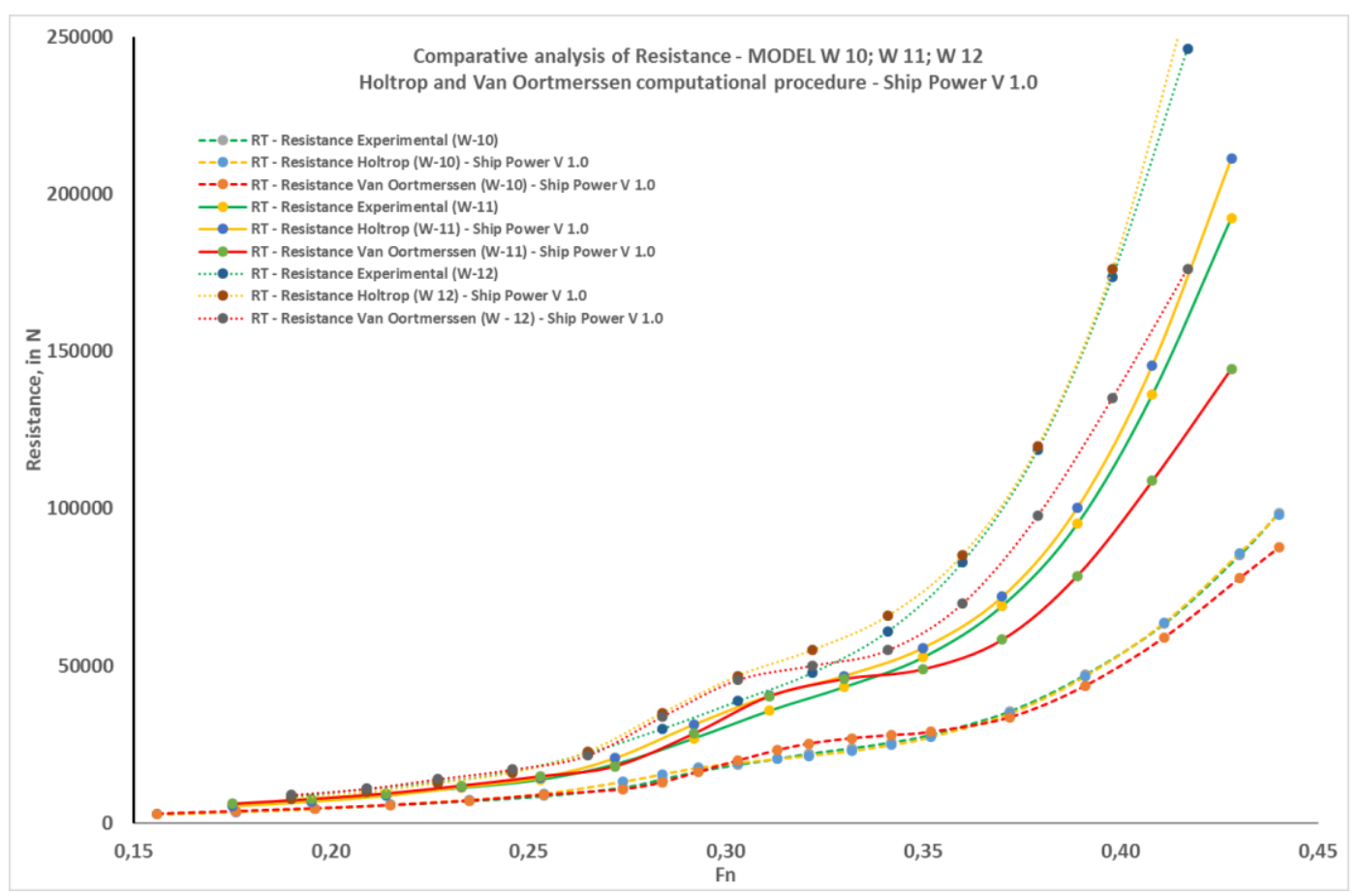

Fig. 11 Graphical comparison of the results of calculations obtained from "Ship Power V 1.0" vs. experimental data for Holtrop and Van Oortmerssen computational procedures

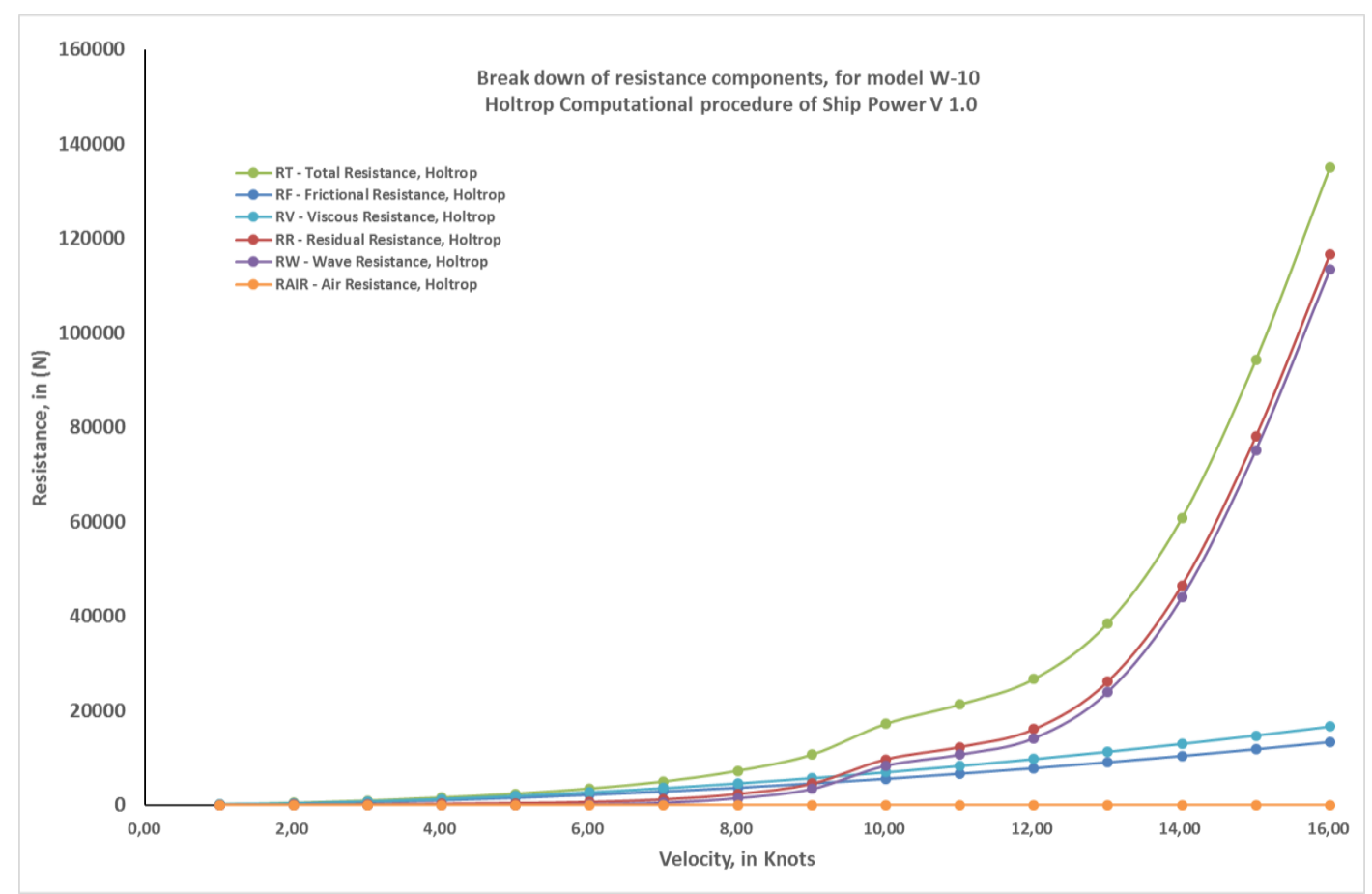

Fig. 12 Break down into resistance components of the W-10 model of the Ridgely-Nevitt trawler series as calculated using the software "Ship Power V 1.0"

\subsection{Analysis of the Kriso Container Ship (KCS)}

Kriso Container Ship (KCS) was the last case taken into consideration for the comparative analysis of the results of calculations of resistance and power according to the computational procedures of the software "Ship Power V-1.0" against the experimental data. In table 1 are presented the main characteristics of this ship as reported in references [38, 39]. Table 2 shows 
the experimental resistance data of this hull as reported in reference [39]. Data presented in table 2 refers to the full-scale resistance data of Kriso Container Ship hull form, extrapolated from the experimental data carried out at the towing tank of the University of Galati, with a $3.502 \mathrm{~m}$ model and reported in [39].

For this case, the comparative analysis of the computational procedures of the software "Ship Power V 1.0" was performed only against the experimental resistance data. The 3D CAD model of the hull was not developed since all the necessary data to run the software Ship Power V 1.0 were available.

The data of the KCS were analysed using the software Ship Power V 1.0, only for the Holtrop computational procedure. In figure 13 is presented the graphic user interface of the software "Ship Power V 1.0" with the parametric data of the KCS. Resistance and power were calculated according to the Holtrop computational procedure for the same velocities as the experimental data. In table 7 are presented the results of calculations according to the Holtrop computational procedure of the software Ship Power V 1.0 and the respective comparisons with experimental data. In figure 14 is presented the graphical comparison of the results of calculations obtained from the software Ship Power V 1.0 versus experimental data for the Holtrop computational procedure.

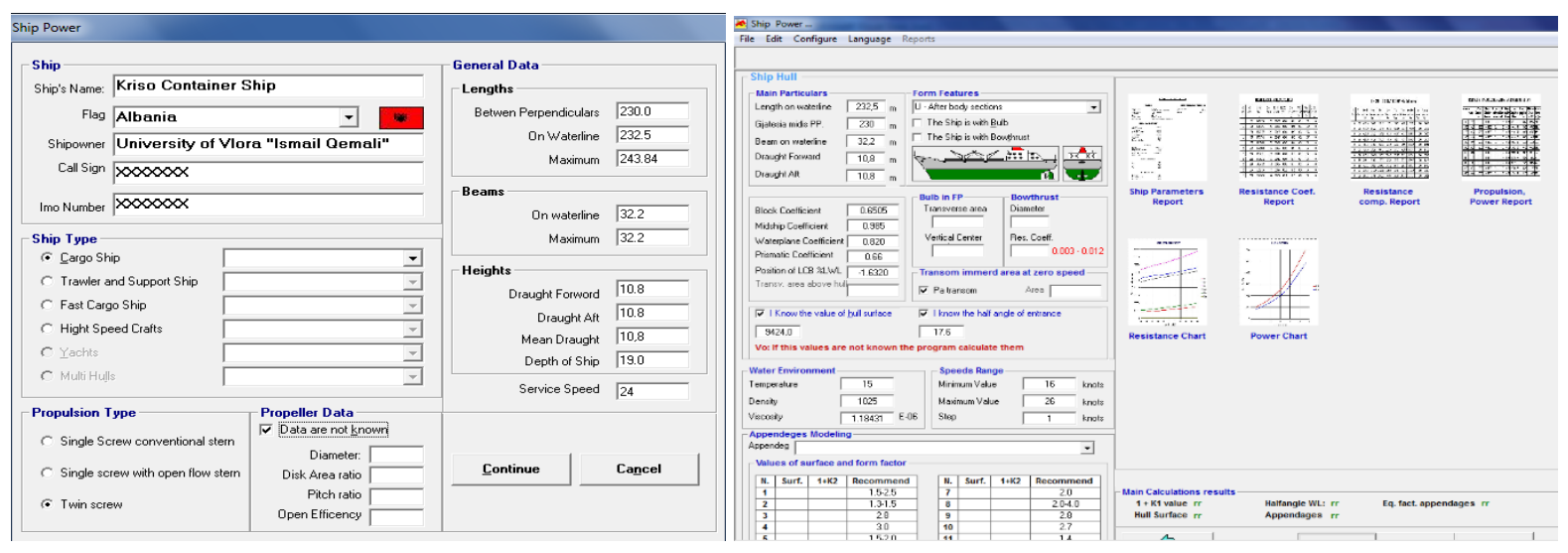

Fig. 13 Graphical User Interface (GUI) of the software "Ship Power V 1.0" with the parametric data of the Kriso Container Ship (KCS)

Table 7 Results of calculations obtained from "Ship Power V 1.0", and comparison with the experimental data for the Kriso Container Ship (KCS)

\begin{tabular}{|c|c|c|c|c|c|}
\hline \multirow{2}{*}{$V s(\mathrm{kn})$} & \multirow{2}{*}{ Froude Number } & Experimental Data - & \multicolumn{3}{|c|}{ Ship Power V 1.0 } \\
\cline { 3 - 6 } & & $R_{T}(\mathrm{KN})[34]$ & $R_{T}(\mathrm{KN})$ & $P E(\mathrm{KW})$ & Dif $(\%)$ \\
\hline 16 & 0.172 & 836.934 & 695.657 & 5725.539 & -16.88 \\
\hline 17 & 0.183 & 874.03 & 800.249 & 6998.017 & -8.44 \\
\hline 18 & 0.194 & 938.772 & 910.510 & 8430.597 & -3.01 \\
\hline 19 & 0.205 & 1044.316 & 1041.586 & 10180.043 & -0.26 \\
\hline 20 & 0.215 & 1167.994 & 1208.924 & 12437.407 & 3.50 \\
\hline 21 & 0.226 & 1292.218 & 1369.639 & 14795.387 & 5.99 \\
\hline 22 & 0.237 & 1451.701 & 1519.626 & 17197.303 & 4.68 \\
\hline 23 & 0.248 & 1617.191 & 1716.329 & 20306.227 & 6.13 \\
\hline 24 & 0.259 & 1857.949 & 2005.631 & 24760.720 & 7.95 \\
\hline 25 & 0.269 & 2289.283 & 2386.474 & 30690.058 & 4.25 \\
\hline 26 & 0.28 & 2827.303 & 2788.553 & 37295.219 & -1.37 \\
\hline
\end{tabular}



parametric software for preliminary predictions of resistance and power

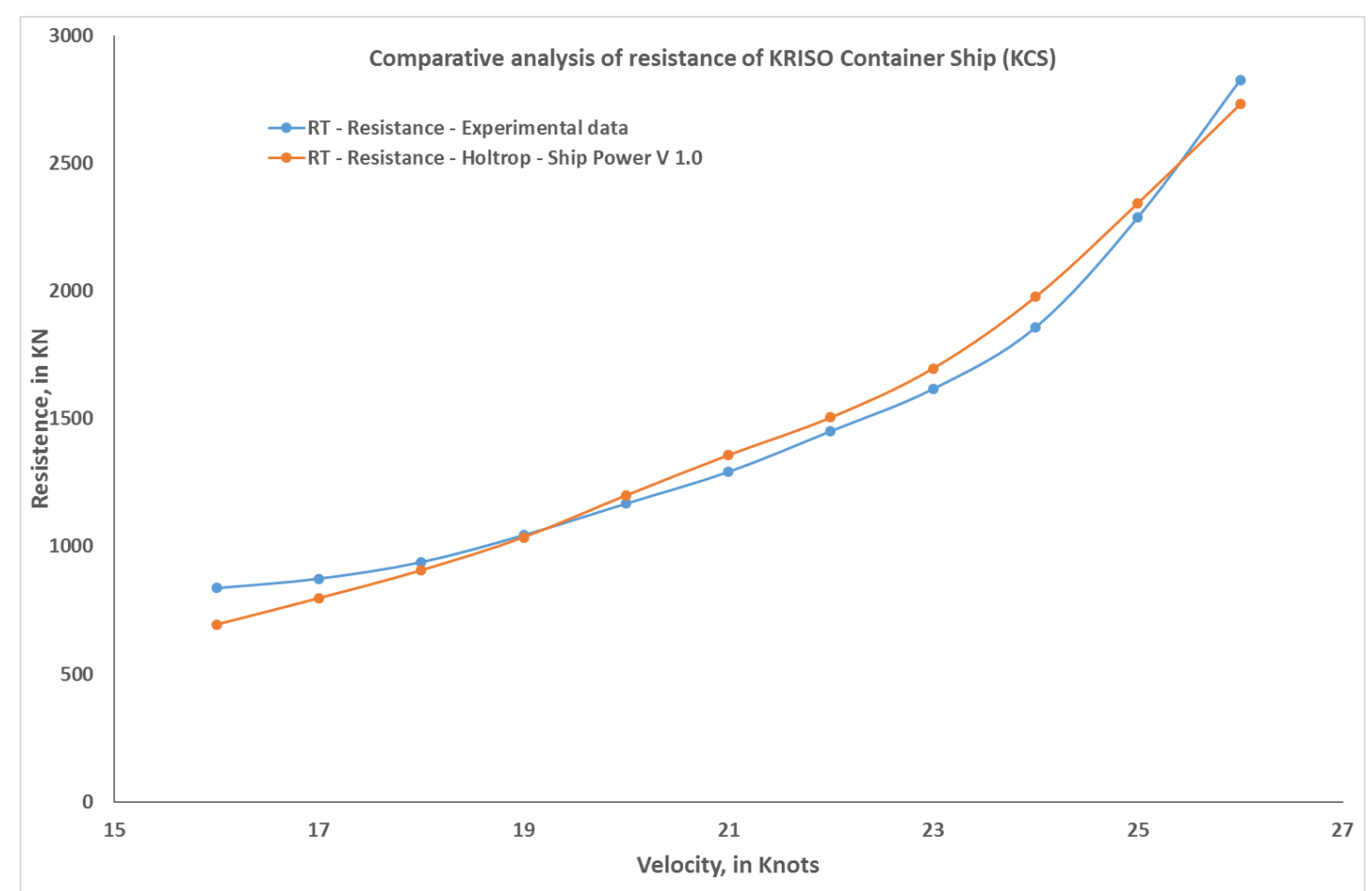

Fig. 14 Graphical comparison of the results of calculations obtained from the software "Ship Power V 1.0" versus experimental data for Holtrop computational procedure

\section{Discussions}

Based on the results of the relative differences of the calculation procedures of Ship Power V 1.0 compared to the experimental data, as presented numerically, and graphically in tables 5, 6, and figure 15 for hulls W-10, W-11, W-12 of Ridgely Nevitt series, and in table 7 for KCS hull, emerge the following discussions.

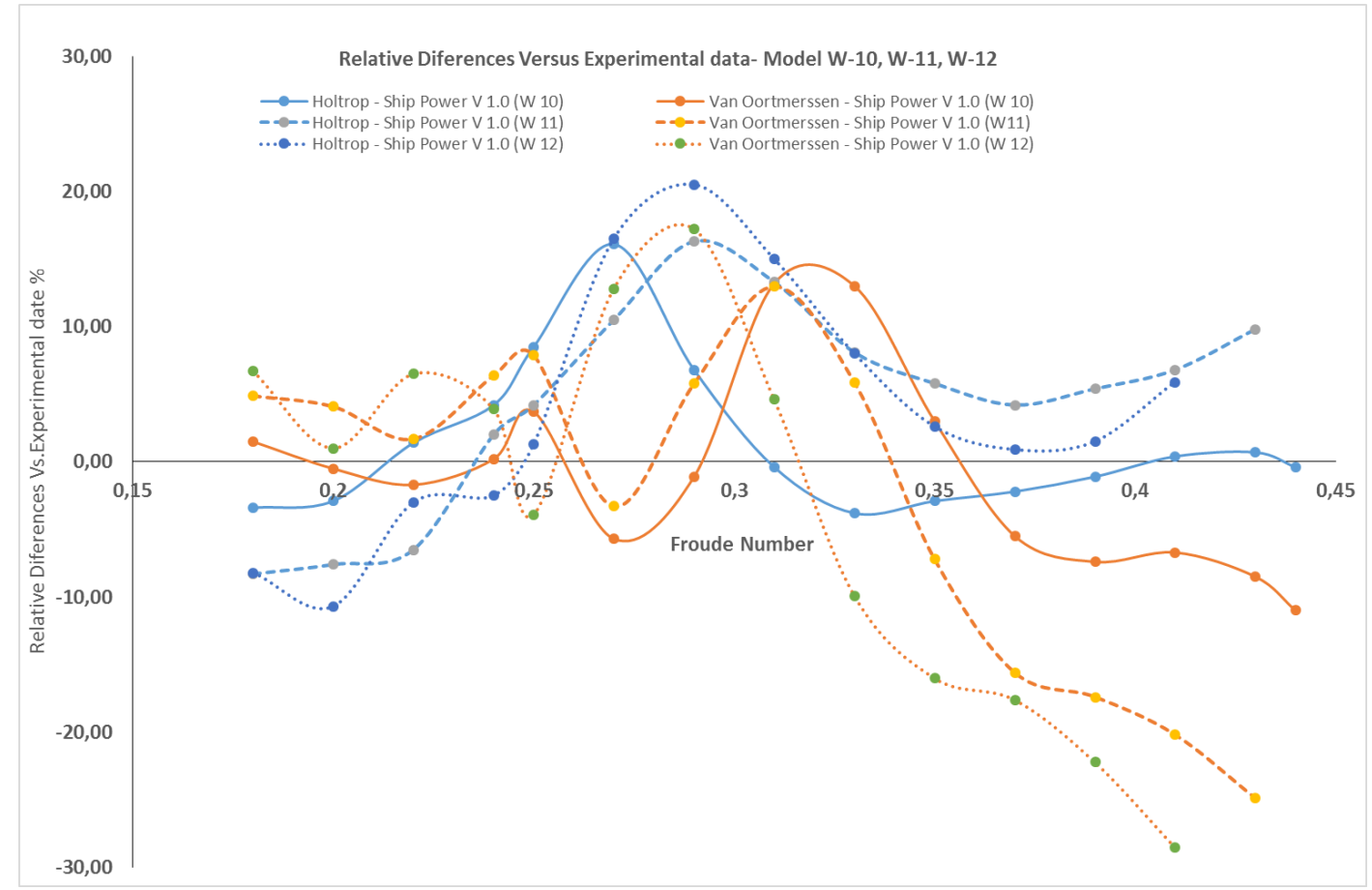

Fig. 15 Relative differences of Ship Power V 1.0 computational procedures versus experimental data, for models W-10, W-11, W-12 of Ridgely Nevitt series 
The Ridgely Nevitt model $\mathrm{W}-10$ has the value of length-beam ratio $L / B=5.546$, beamdraft ratio $B / T=2.29$, prismatic coefficient $C_{P}=0.65$. Speeds and the respective Froude numbers correspond to the range between $0.16 \leq F r \leq 0.44$. All geometrical parameters of this hull are within the limits of the application of the Holtrop and Van Oortmersen regressions. The 3D model of the $\mathrm{W}-10$ hull of the Ridgely Nevitt trawler series obtained through the reconstruction procedure presented in figure 3 fitted very well the real model. The geometrical and hydrostatic parameters of the 3D model were very close to the main parameters presented in Table 1, assuring a better accuracy of the prediction of resistance obtained during the analysis.

In the case of the Holtrop-Mennen computational procedure for the model W-10, the results of calculations highlight that, for Froude numbers, $0.16 \leq F n \leq 0.20$ calculated resistance according to the Holtrop-Mennen underestimates measured data, where the values of the relative differences oscillate in the range $[-1.9 \% \div-3.4 \%]$ with the increase of Froude numbers. The average relative difference between calculated and measured data in this interval of Froude Numbers is $-2.7 \%$. For Froude numbers, $0.22 \leq F n \leq 0.30$ the calculated resistance according to the Holtrop Mennen overestimates measured data, where the values of relative differences oscillate in the range $[1.4 \% \div 16.1 \%]$ with the increase of Froude number. The average relative difference between calculated and measured data in this interval of Froude Numbers is $7.2 \%$. In the case of Froude numbers, $0.31 \leq F n \leq 0.39$ the calculated resistance according to the Holtrop-Mennen underestimates measured data, where values of the relative differences oscillate in the range $[-0.4 \% \div-3.8 \%]$ with the increase of Froude number. The average relative difference between the calculated and measured data in this interval of Froude Numbers is -2.4 $\%$. In the case of Froude numbers, $0.41 \leq F n \leq 0.43$ the calculated resistance according to the Holtrop-Mennen overestimates measured data. The average relative difference between the calculated and measured data in this interval of Froude Numbers is $0.54 \%$.

In the case of the Van Oortmersen computational procedure for the model $\mathrm{W}-10$, the results of calculations highlight that, for Froude numbers, $0.16 \leq F n \leq 0.18$ calculated resistance according to the Van Oortmersen overestimates the measured data. The average relative difference between calculated and measured data in this interval of Froude Numbers is $2.1 \%$. For Froude numbers, $0.20 \leq F n \leq 0.22$ calculated resistance according to the Van Oortmerssen underestimates the measured date. The average relative difference between calculated and measured data in this interval of Froude Numbers is $-1.1 \%$. For Froude numbers, $0.24 \leq F n$ $\leq 0.25$ calculated resistance according to the Van Oortmerssen overestimates the measured date. The average relative difference between calculated and measured data in this interval of Froude Numbers is $1.9 \%$. For Froude numbers, $0.27 \leq F n \leq 0.29$ calculated resistance according to the Van Oortmerssen underestimates the measured date, where the values of relative differences oscillate in the range $[-1.1 \% \div-7.3 \%]$ with the increase of Froude number. The average relative difference between calculated and measured data in this interval of Froude Numbers is $-4.7 \%$. For Froude numbers, $0.30 \leq F n \leq 0.35$ the calculated resistance according to the Van Oortmersen overestimates measured data, where the values of relative differences oscillate in the range [3.0 $\% \div 14.1 \%]$ with the increase of Froude number. The average relative difference between calculated and measured data in this interval of Froude Numbers is $9.7 \%$. For Froude numbers, $0.37 \leq F n \leq 0.44$ the calculated resistance according to the Van Oortmersen underestimates measured data, where the values of relative differences oscillate in the range $[-5.5 \% \div-11.0$ $\%$ ] with the increase of Froude number. The average relative difference between the calculated and measured data in this interval of Froude Numbers is $-7.8 \%$.

The Ridgely Nevitt model W-11 has the value of length-beam ratio $L / B=3.92$, beamdraft ratio $B / T=2.29$, prismatic coefficient $C_{P}=0.65$. Speeds and the respective Froude 
numbers correspond to the range between $0.18 \leq F n \leq 0.43$. All geometrical parameters of this hull are within the limits of the application of the Holtrop and Van Oortmersen regressions. Regarding the applicability of the Holtrop regression, it is noted that the value of the $L / B$ ratio is just at the lower limit of the recommended values. The 3D model of the $\mathrm{W}-11$ hull of the Ridgely Nevitt trawler series obtained through the reconstruction procedure presented in figure 3 fitted very well the real model. The geometrical and hydrostatic parameters of the 3D model were very close to the main parameters presented in Table 1, assuring a better accuracy of the prediction of resistance obtained during the analysis.

In the case of the Holtrop-Mennen computational procedure for the model W-11, the results of calculations highlight that for Froude numbers $0.18 \leq F n \leq 0.22$ calculated resistance according to the Holtrop Mennen underestimates measured data, where the values of relative differences oscillate in the range $[-6.5 \% \div-8.30 \%]$ with the increase of Froude numbers. The average relative difference between calculated and measured data in this interval of Froude Numbers is $-7.5 \%$. For Froude numbers, $0.24 \leq F n \leq 0.43$ the calculated resistance according to the Holtrop-Mennen overestimates measured data, where the values of relative differences oscillate in the range $[2.0 \% \div 16.3]$ with the increase of Froude number. The average relative difference between the calculated and measured data in this interval of Froude Numbers is 7.9 $\%$.

In the case of the Van Oortmersen computational procedure for the model W-11, the results of calculations highlight that, for Froude numbers, $0.18 \leq F n \leq 0.33$ calculated resistance according to the Van Oortmersen overestimates measured data, except the Froude Number $F n=0.27$ for which there is an underestimation of $-3.30 \%$ of the measured resistance. For Froude Numbers $0.18 \leq F n \leq 0.25$ calculated resistance according to the Van Oortmerssen overestimates measured data, where the values of relative differences oscillate in the range $[1.7 \% \div 7.9 \%]$ with the increase of Froude number. The average relative difference between calculated and measured data in this interval of Froude Numbers is $5.0 \%$. For Froude numbers, $0.29 \leq F n$ $\leq 0.33$ calculated resistance according to the Van Oortmersen overestimates measured data, where the values of relative differences oscillate in the range $[5.8 \% \div 13.0 \%]$ with the increase of Froude number. The average relative difference between the calculated and measured data in this interval of Froude Numbers is $8.2 \%$. For Froude numbers, $0.35 \leq F n \leq 0.43$ the calculated resistance according to the Van Oortmersen underestimates measured data, where the values of relative differences increase in the range $[-7,2 \% \div-24.9 \%]$ with the increase of Froude number. The average relative difference between calculated and measured data in this interval of Froude Numbers is $-17.0 \%$.

The Ridgely Nevitt model W-12 has the value of length-beam ratio $L / B=3.512$, beamdraft ratio $B / T=2.29$, prismatic coefficient $C_{P}=0.65$. Speeds and the respective Froude numbers correspond to the range between $0.19 \leq F n \leq 0.42$. Regarding the Holtrop regression, it is noted that the value of the length/beam ratio is below the lower limit of the recommended values by approximately $10 \%$. While regarding the Van Oormerssen regression, all the geometrical parameters of this hull are within limits of the applicability. The 3D model of the W-12 hull of the Ridgely Nevitt trawler series obtained through the reconstruction procedure presented in figure 3 fitted very well the real model. The geometrical and hydrostatic parameters of the 3D model were very close to the main parameters presented in Table 1, assuring a better accuracy of the prediction of resistance obtained during the analysis.

In the case of the Holtrop-Mennen computational procedure for the model W-12, the results of calculations highlight that for Froude numbers $0.20 \leq F n \leq 0.25$ calculated resistance according to the Holtrop Mennen underestimates measured data, where values of relative differences oscillate in the range $[-2.5 \% \div-10.7 \%]$ with the increase of Froude numbers. The 
average relative difference between calculated and measured data in this interval of Froude Numbers is $-6.1 \%$. For Froude numbers, $0.27 \leq F n \leq 0.43$ the calculated resistance according to the Holtrop Mennen overestimates measured data where values of relative differences oscillate in the range $[0.9 \% \div 20.5 \%]$ with the increase of Froude number. The average relative difference between calculated and measured data in this interval of Froude Numbers is $8.0 \%$.

In the case of the Van Oortmersen computational procedure for the model W-12, the results of calculations highlight that for Froude numbers $0.20 \leq F n \leq 0.33$ calculated resistance according to the Van Oortmersen overestimates measured data, except the Froude Number $F n=0.27$ for which there is an underestimation of $-3.9 \%$ of the measured resistance. For Froude Numbers $0.20 \leq F n \leq 0.25$ calculated resistance according to the Van Oortmerssen overestimates measured data where values of relative differences oscillate in the range $[1.0 \% \div 6.7 \%]$ with the increase of Froude number. The average relative difference between calculated and measured data in this interval of Froude Numbers is $4.5 \%$. For Froude numbers, $0.29 \leq \mathrm{Fn} \leq 0.33$ the calculated resistance according to the Van Oortmersen overestimates measured data, where values of the relative differences oscillate in the range $[4.6 \% \div 17.2 \%$ ] with the increase of Froude number. The average relative difference between calculated and measured data in this interval of Froude Numbers is $11.6 \%$. For Froude numbers, $0.35 \leq F n \leq 0.43$ the calculated resistance according to the Van Oortmersen underestimates measured data, where values of relative differences increase in the range $[-9.9 \% \div-28.5 \%]$ with the increase of Froude number. The average relative difference between calculated and measured data in this interval of Froude Numbers is $-18.8 \%$. This range of Froude numbers is the zone where the calculated resistance represents the higher deviations from the measured data.

The discussions of the results of the numerical analysis discussed in this section for models W-10, W-11, and W-12 for the Ridgley Nevitt trawler series has also shown that the Holtrop computational procedure of the software "Ship Power V 1.0" has the best-predicting accuracy for the model W-10, which has all the geometrical parameters within the recommended values of the applicability of the Holtrop regression model. The predictive accuracy worsens for the W-11 model, which has one of the parameters at the limits of the recommended values of the applicability of the Holtrop regression model. The computational procedure has shown the worst level of approximation for the model $\mathrm{W}-12$, which has one of the geometrical parameters outside the recommended values of the applicability of the Holtrop regression model. This means that in the case of using the Holtrop and Van Oortmerssen computational procedures of the software "Ship Power V 1.0" care must be shown that type of ships, velocity, and main geometrical parameters must be within the range of the applicability of the regressions models Holtrop, and Van Oortmerssen, as reported in references [11, $12,13,14,24,25,26]$.

The hull of Kriso Container Ship (KCS) has the value of length-beam ratio $L / B=7.14$, beam-draft ratio $B / T=2.98$, prismatic coefficient $C_{P}=0.66$. Speeds and the respective Froude numbers correspond to the range between $0.17 \leq F n \leq 0.28$. All parameters are within limits of the application of the Holtrop regression-based method.

The data of the KCS were analysed by the software Ship Power V 1.0, and the prediction of resistance was performed only for the Holtrop computational procedure since Van Oortmerssen regression is not suitable for the parameters of the hull of this ship. The results of calculations presented in table 7 highlight that, for Froude numbers, $0.17 \leq F n \leq 0.21$ calculated resistance according to the Holtrop Mennen underestimates measured data, where values of relative differences are in the range $[-0.26 \% \div-16.88 \%]$. Relative differences gradually decrease with the increase of the Froude number. The average relative difference between calculated and measured data in this interval of Froude Numbers is $-7.15 \%$. For Froude numbers, $0.22 \leq F n \leq 0.27$ calculated resistance according to the Holtrop Mennen overestimates 
measured data where values of relative differences oscillate in the range $[3.5 \% \div 7.95 \%]$ with the increase of Froude number. The average relative difference between calculated and measured data in this interval of Froude Numbers is $5.42 \%$.

Figure 16 shows the graph of the relative differences as a function of the Froude number, referred to the Holtrop and Van Oortmerssen computational procedure of "Ship Power V1.0" for the hull of Kriso Container Ship (KCS).

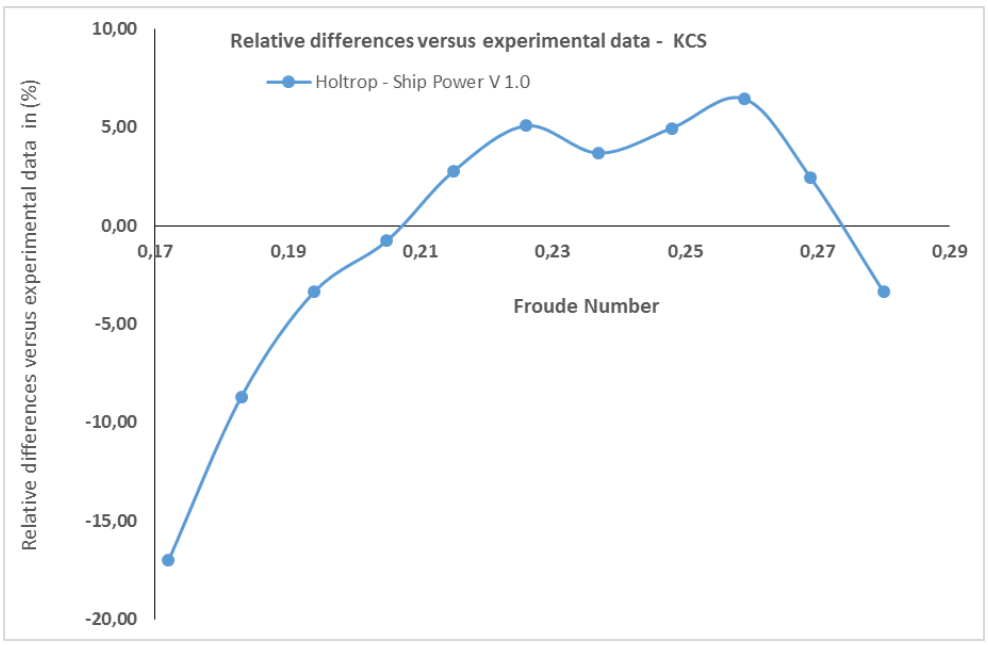

Fig. 16 Relative differences as a function of Froude Number for the Kriso Container Ship (KCS) - Holtrop computational procedure of "Ship Power V 1.0"

Concluding the discussion section of this paper, based on the discussed results of this study, it can also be pointed out that when using the Holtrop and Van Oortmerssen computational procedures of the software "Ship Power V 1.0" care must be shown that not only the type of ships must be within the range of the applicability of the regressions models Holtrop (tankers, bulk carriers, general cargo, fishing vessels, tugs, container ships, frigates, $[11,25]$ ), and Van Oortmerssen (small ships such as tugs, fishing boats, stern trawlers, pilot boats, etc., $[14,24,25,26])$, but also the velocity and main geometrical parameters must be with the range of the applicability, as reported in references [11, 12, 13, 14, 24, 25, 26].

\section{Conclusions}

Results of the comparative analysis, versus experimental data, of two computational procedures of the software "Ship Power V 1.0", developed by the author, based on the regression models Holtrop Mennen and Van Oortmerssen, were presented in this study. The comparative analysis was carried out based on the experimental results of three models of the well-known Ridgely-Nevitt trawler hull form series, experimental data of the Kriso Container Ship (KCS), and the outputs of the computational procedures Holtrop and Van Oortmerssen of "Ship Power V 1.0". A procedure that combines the capability of the software "Ship Power V1.0" with other CAD platforms and geometric modelling techniques used for the comparative analysis was also presented in this study. The procedure can also be applied for a preliminary and rapid prediction of resistance of existing hulls, lacking both geometric and resistance data. In this case, the cloud of points for the 3D CAD modelling of the hull can be obtained either by using traditional manual physical measurements or by using 3D laser scanner measurements. For all the analysed hulls (Ridgely Nevitt trawler hulls and KCS), both computational procedures, developed in "Ship Power V1.0", based on the regression models Holtrop and Van Oortmerssen, have shown a good level of accuracy compared to the experimental data. Additionally, the software "Ship Power V 1.0" has shown excellent performances compared to other well-known commercial software. Therefore, Ship Power V 1.0 can be considered a 
reliable tool like other well-known commercial software for preliminary predictions of resistance and power of ships.

The performed comparative analysis highlighted the following detailed conclusions:

- The comparative analysis presented in sections 3 and 4 shows that the results of the Holtrop computational procedure of "Ship Power V1.0" are closer to the experimental data than the results of the Van Oortmerssen computational procedure.

- The comparative analysis of the hulls of the Ridgely-Nevitt models shows that for speeds up to 10 knots, which corresponds to Froude numbers up to $F n \cong 0.29$, both computational procedures, Holtrop Mennen and Van Oortmerssen, have a very satisfactory level of accuracy against experimental data. For the speed range of [10-

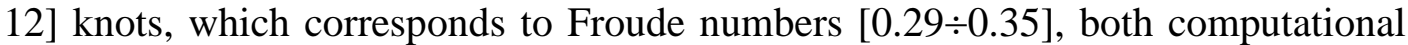
procedures of "Ship Power V 1.0" have found the trend of experimental data, approximating the experimental data. For speeds above 12 knots which correspond to Froude numbers $F n \geq 0.3$, the Holtrop computational procedure has relatively a satisfactory level of accuracy compared to experimental data and a better level of approximation than the Van Oortmerssen computational procedure.

- The comparative analysis performed on the Ridgely-Nevitt models shows that the Holtrop computational procedure of "Ship Power V 1.0" has the best approximation level for the model W-10, which has all the geometrical parameters within the recommended values of the applicability of the Holtrop regression. The procedure has shown the worst level of approximation for the model W-12, which has one of the geometrical parameters outside the recommended values of the applicability of the Holtrop regression.

- Although the comparative analysis was performed only for three models of the Ridgley Nevitt series, based on the results of this study, the opinion of the author is that, for the Ridgley Nevitt trawler series, the Holtrop computational procedure has a satisfactory level of approximation within the entire range of velocities, showing the best performances for speeds values up to about 9-10 knots and Froude Numbers 0.26-0.29. While the Van Oortmerssen worsens the computational performances compared to the Holtrop computational procedure for Froude numbers, $F n \geq 0.35$.

- Even in the case of the hull of Kriso Container Ship (KCS), the comparative analysis shows that the computational procedure of Ship Power V 1.0 based on the Holtrop Mennen regression has a good level of approximation of experimental data, presenting relative differences to experimental data of order of $\pm 5 \%$, in the case of Froude Numbers $[0.19 \div 0.28]$, while in the case of Froude Numbers $[0.17 \div 0.19]$ the relative differences are in the range $[-16.88 \% \div-9.44 \%]$.

- Results of the comparative analysis of calculations of "Ship Power V 1.0" versus other well-known commercial software performed on hulls of Ridgely Nevitt trawler hull series shown good accuracy of results, meaning that "Ship Power V 1.0" is a reliable tool for prediction of resistance and power of ships, as well as other wellknown commercial software.

- Results of this study highlight that both computational procedures of the software "Ship Power V 1.0" can be used in the preliminary phase of the ship design process for predicting the resistance and power.

Future work. Despite the results of this study, additional investigations and future studies are needed to validate the computational procedures of the software "Ship Power V 1.0" for other conventional hulls forms, such as low-speed hulls, tankers, bulk carriers, general cargo, 
tugs, pilot boats, etc., in order to understand the prediction accuracy of the software also for these types of hulls.

\section{REFERENCES}

[1] Molland, A., 2008. The Maritime Reference Book - A guide to design, construction and operation. Butter Worth-Heinemann.

[2] Roh, M., Lee K., 2018. Computational Ship Design. Springer Nature Singapore Pte Ltd., https://doi.org/10.1007/978-981-10-4885-2

[3] Trincas, G., 2010. Complementi di Propulsione Navale - Lectures Notes - University of Trieste, Trieste.

[4] Chirosca, A., Rusu, L., 2021. Comparison between Model Test and Three CFD Studies for a Benchmark Container Ship. Journal of Marine Science Engineering, 9(1), 62. https://dx.doi.org/10.3390/jmse9010062

[5] Degiuli, N., Farkas, A., Martic, I., Zeman, I., Ruggiero, V., Vasiljevic, V., 2021. Numerical and experimental assessment of the total resistance of a yacht. Brodogradnja, 72(3), 61-80. http://dx.doi.org/10.21278/brod72305

[6] Zhao, C., Wang, W., Jia, P., Xie, Yh., 2021. Optimization of hull form of ocean-going trawler. Brodogradnja, 72(4), 33-46. http://dx.doi.org/10.21278/brod72403

[7] Farkas, A., Deguili, N., Martic, I., 2017. Numerical simulation of viscous flow around a tanker model”, Brodogradnja, 68(2), 109-125. http://dx.doi.org/10.21278/brod68208

[8] Solak, HP., 2020. Multi-dimensional surrogate based aft form optimization of ships using high fidelity solvers. Brodogradnja, 71(1), 85-100. http://dx.doi.org/10.21278/brod71106

[9] Ozdemir, YH., Barlas, B., 2018. Free surface flow simulation around an appended ship hull. Brodogradnja, 69(3), 25-41. http://dx.doi.org/10.21278/brod69302

[10] Nikolopoulos, L., Boulougouris, E., 2019. A Study on the Statistical Calibration of the Holtrop and Mennen Approximate Power Prediction Method for Full Hull Form, Low Froude Number Vessels. Journal of Ship Production and Design, 35(1), 41-68. http://dx.doi.org/10.5957/JSPD.170034

[11] Holtrop, J., 1977. A Statistical analysis of performance test results. International Shipbuilding Progress, 24. https://doi.org/10.3233/ISP-1977-2427001

[12] Holtrop, J., Mennen, G.G.J., 1982. An approximate power prediction method. International Shipbuilding Progress, 29(335), 166-170. https://doi.org/10.3233/ISP-1982-2933501

[13] Holtrop, J., 1984. A statistical re-analysis of resistance and propulsion data. International Shipbuilding Progress, 1984(31), 272-276.

[14] Oortmerssen, G. V., 1971. A power prediction method and its application to small ships. International Shipbuilding Progress, 12(207), 397-415. https://doi.org/10.3233/ISP-1971-1820701

[15] Hollenbach, K.U., 1988. Estimating Resistance and Propulsion for Single Screw and Twin Screw Ships. Ship Technology Research, 45, 72-76.

[16] Karczewski, A., Kozak, J., 2017. Variant designing in the preliminary small ship design process. Polish Maritime Research, 24(2), 77-82. https://dx.doi.org/10.1515/pomr-2017-0052.

[17] Priftis, A., Boulougouris, E., Turan, O., 2016. Parametric design and multi-objective optimisation of containerships, Proceedings of International Conference on Maritime Safety and Operations, Glasgow, UK.

[18] Ang, J., H., Goh H., Choo C., T., Juveno, Lee, Z. M., Jirafe, V.J., Li, W., 2019. Evolutionary Computation Automated Design of Ship Hull Forms for the Industry 4.0 Era. Proceedings of IEEE Congress on Evolutionary Computation (CEC), 2347-2354, New Zealand. https://doi.org/10.1109/CEC.2019.8789905

[19] Choo, C. T., Ang, J. H., Kuik, S., L. C. Hui M., Li, Y., Goh, C., 2020. Ship Design with a Morphing Evolutionary Algorithm. Proceedings of IEEE Congress on Evolutionary Computation (CEC), 1-8. https://doi.org/10.1109/CEC48606.2020.9185645

[20] Jung, Y. W., Kim, Y., 2019. Hull form optimization in the conceptual design stage considering operational efficiency in waves. Journal of Engineering for the Maritime Environment, 233(3), 745-759. https://dx.doi.org/10.1177/1475090218781115

[21] Deng, R., Wang, Sh., Hu, Y., Wang, Y., Wu, T., 2021. The Effect of Hull Form Parameters on the Hydrodynamic of a Bulk Carrier. Journal of Marine Science and Engineering, 9(4), 373. https://dx.doi.org/10.3390/jmse9040373 
[22] Kim, S., Roh, M., Oh, M., Park, S., Kim, I., 2020. Estimation of ship operational efficiency from AIS data using big data technology. International Journal of Naval Architecture and Ocean Engineering, 12, 440454. https://dx.doi.org/10.1016/j.ijnaoe.2020.03.007

[23] Xhaferaj, B., Dukaj, A., 2012. A computer program for prediction of resistance and power of ship. International Conference on Ship and Shipping Research, Naples, Italy.

[24] Helmore, P., 2008. Update on Van Oortmerssen's Resistance Prediction. Proceedings of Pacific International Maritime Conference, Sydney, Australia.

[25] Molland, A., Turnock, S. R., Hudson, D. A., 2011. Ship resistance and propulsion - practical estimation of ship propulsive power. Cambridge University Press, https://doi.org/10.1017/CBO9780511974113

[26] Xhaferaj, B., Dukaj, A., 2017. A new procedure of power prediction based on Van Oortmerssen regression. Proceedings of IMAM 2017 - Maritime Transportation and Harvesting of Sea Resources, 387-392. ISBN 9780815379935.

[27] Manen, J. V., Oossanen, V., 1988. Principles of Naval Architecture - Resistance - Volume II, chapter V, 29-34, SNAME.

[28] Papanikolaou, A., 2014. Ship Design - Methodology for preliminary ship design. Springer, 2014, Dordrecht, Netherlands.

[29] Watson, D.G.M., 1998. Practical Ship Design. Volume 1, Elsevier Science.

[30] Bertram, V., 2002. Ship Design for Efficiency and Economy. $2^{\text {nd }}$ Edition, Butterworth-Heinemann.

[31] Obreja, D., Bahrim, B. I., 2015. Computation of main dimensions and form coefficients in initial ship design, Annals of "Dunarea de Jos" University of Galati, ISSN 1221-4620.

[32] Xhaferaj, B., 2015. Modeling of ship hulls in the CAD environment and development of computer program for evaluating propulsive characteristics of marine vessels. PhD Thesis, in Albanian.

[33] Xhaferaj, B., Kasemi, V., Duka, M., 2010. Design of ship hull surface using modern modeling technique (in Albanian). Journal of Albanian Science Institute - AKTET, 3(2), 261-267.

[34] Xhaferaj, B., Kasemi, V., 2008. Use of Maxsurf software package for the evaluation of the nautical qualities of Albanian ships (in Albanian). Proceeding of national symposium Materials and the reliability of Albanian Maritime System, ISBN 9789995-67-42-67.

[35] Xhaferaj, B., Lapa, K., 2014. A case study on the prediction of some hydrodynamic characteristics of a small marine vehicle. Proceedings of International Maritime Science Conference - IMSC 2014, Solin, Croatia.

[36] Nevitt C. R., 1963. The development of parent hulls for a high displacement length series of trawler forms. Transactions of the Society of Naval Architects and Marine Engineers, SNAME, 73.

[37] Claytor, R., Eareckson, L., Wilkins, J. R., 1956. The resistance of trawler hull forms of various displacement-length ratios at 0, 65 prismatic coefficient. Master Thesis, WEBB Institute.

[38] MOERI Container Ship (KCS), 2021. Online: http://www.simman2008.dk/KCS/container.html, accessed: 19 August 2021.

[39] Ouargli, H., 2015. Hydrodynamic Performances of KRISO Container Ship (KCS) Using CAD-CAE and CFD Techniques, Master Thesis, EMSHIP - Integrated Advanced Ship Design, University of Liege.

Submitted: $\quad$ 22.11.2021. Blenard Xhaferaj, blenardxhaferaj@yahoo.it University of Vlora "Ismail Qemali" - Albania Department of Engineering and Marine Technology

Accepted: $\quad$ 27.01.2022. 